\title{
LA EMERGENCIA DE LOS LÍMITES \\ CONSTITUCIONALES DE LA CONFIANZA MUTUA \\ EN EL ESPACIO DE LIBERTAD, SEGURIDAD Y JUSTICIA EN LA SENTENCIA DEL TRIBUNAL DE JUSTICIA ARANYOSI Y CĂLDĂRARU
}

\author{
PABLO J. MARTÍN RODRÍGUEZ \\ pamartin@ugr.es
}

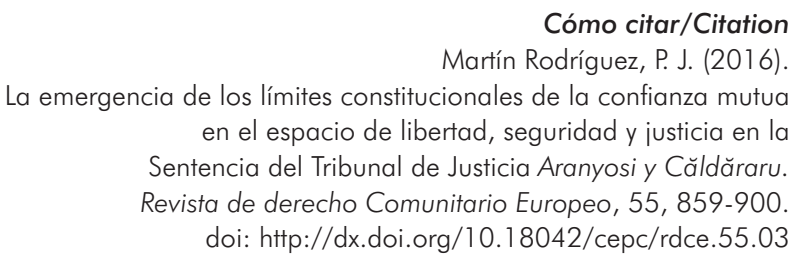

Resumen

Este trabajo analiza la excepción admitida por el Tribunal de Justicia en la Sentencia de 5 de abril de 2016, Aranyosi y Căldăraru (C-404/15 y C-659/15 PPU) desde la perspectiva de la protección de derechos fundamentales en el derecho de la Unión Europea. Se sostiene que esta trascendental jurisprudencia da una respuesta correcta, obligatoria desde la perspectiva del derecho primario, a un tipo concreto de los problemas de respeto de derechos fundamentales en el funcionamiento del espacio de libertad, seguridad y justicia, consistente en la desaparición de su presupuesto normativo: la confianza mutua tal y como ha sido concebida en la jurisprudencia. Sin embargo, la diferenciación clara entre la confianza mutua y el reconocimiento mutuo permite afirmar que no es un expediente apto para resolver otros tipos de problemas

\footnotetext{
Profesor titular de Derecho Internacional Público y Relaciones Internacionales de la Universidad de Granada. El presente trabajo se ha realizado en el marco del Proyecto de Investigación DER2014-57213-R financiado por el Ministerio de Economía y Competitividad.
} 
de respeto de estos derechos derivados de las debilidades de las normas del antiguo tercer pilar o de las opciones normativas arriesgadas o negligentes del legislador europeo contenidas en tales normas, respecto de los cuales la admisión de una excepción genérica al reconocimiento mutuo no viene impuesta por el derecho originario.

\section{Palabras clave}

Orden europea de detención y entrega; confianza mutua; reconocimiento mutuo; derechos fundamentales.

\section{THE EMERGENCE OF THE CONSTITUTIONAL LIMITS TO MUTUAL TRUST WITHIN THE AREA OF FREEDOM, SECURITY AND JUSTICE IN JUDGMENT ARANYOSI AND CĂLDĂRARU OF THE COURT OF JUSTICE}

\section{Abstract}

This article analyses the exception admitted by the European Court of Justice in the Judgment of 5 April 2016 Aranyosi and Căldăraru (Cases C-404/15 and C-659/15 PPU) from the point of view of the protection of fundamental rights in EU law. It is suggested that this landmark case law gives the proper answer to just one type of fundamental rights concerns in the area of freedom, security and justice, which is the disappearance of mutual trust between member states as tailored by ECJ case law. However, by clearly differentiating between mutual trust and mutual recognition, it is submitted here that this case law does not offer an adequate solution for other types of fundamental rights concerns, such as those stemming from structural normative weakness of the old third pillar norms or from risky or negligent legislative choices foreseen in those norms. In the latter cases, the admission of a general human rights exception to mutual recognition is not necessarily deduced from EU primary law.

\section{Keywords}

European Arrest Warrant; mutual trust; mutual recognition; fundamental rights.

\section{L'ÉMERGENCE DES LIMITES CONSTITUTIONNELLES À LA CONFIANCE MUTUELLE DANS L'ESPACE DE LIBERTÉ, SÉCURITÉ ET JUSTICE DANS L'ARRÊT ARANYOSI ET CĂLDĂRARU DE LA COUR DE JUSTICE}

\section{Résumé}

Cet article analyse l'exception admise pour la Cour de justice dans l'arrêt du 5 avril 2016 Aranyosi et Căldăraru (C-404/15 et C-659/15 PPU) du point de vue de la 
protection des droits fondamentaux au droit de l'Union européenne. On évoque que cette jurisprudence donne une réponse correcte, même imposée par le droit primaire, à un type des problèmes du respect des droits fondamentaux posés dans l'espace de liberté, sécurité et justice, notamment celui de la disparition de sa prémisse normative : la confiance mutuelle tel que comprise par la jurisprudence de la Cour. Cependant, on soutient que la différentiation claire entre confiance mutuelle et reconnaissance mutuelle permet d'affirmer que cette solution n'est pas appropriée pour résoudre d'autres types des problèmes posés comme ceux dérivés de la faiblesse normative des normes de l'ancien troisième pilier ou bien des options régulatrices risquées ou négligentes y consacrées. Pour les dernières, l'admission d'une exception générique à la reconnaissance mutuelle ne vient pas imposée par le droit originaire

\section{Mots clés}

Mandat d'arrêt européen; confiance mutuelle; reconnaissance mutuelle; droits fondamentaux. 


\section{SUMARIO}

I. INTRODUCCIÓN. II. PREMISA PRIMERA: LOS PROBLEMAS DE PROTECCIÓN DE LOS DERECHOS FUNDAMENTALES EN LA COOPERACIÓN JUDICIAL PENAL DE LA UNIÓN. III. PREMISA SEGUNDA: UN SUPUESTO DE HECHO PARADIGMÁTICO DE UN PROBLEMA DE FONDO: LAS CONDICIONES DE LOS CENTROS DE DETENCIÓN Y RECLUSIÓN EN LOS ESTADOS MIEMBROS. IV. PREMISA TERCERA: EL INCIERTO SUSTRATO JURÍDICO DE LA CUESTIÓN EN DERECHO SECUNDARIO. V. LA SOLUCIÓN PROPUESTA POR EL ABOGADO GENERAL: RECHAZO DE LA EXCEPCIÓN Y ALGO MÁS QUE PROPORCIONALIDAD. VI. LA SOLUCIÓN DEL TRIBUNAL: LA ACEPTACIÓN DE UNA «EXCEPCIÓN» SEVERAMENTE PROCEDIMENTALIZADA PERO DE PERFILES INCIERTOS. VII. LA JUSTIFICACIÓN DE LOS LÍMITES «CONSTITUCIONALES» DE LA CONFIANZA MUTUA: 1. Diferenciando reconocimiento mutuo y confianza mutua; 2 . Los límites de derecho originario de la confianza mutua y la justa medida en que la cuestión competencial es relevante; 3. Recuperando la diferencia entre confianza mutua y reconocimiento mutuo desde la perspectiva de sus límites «constitucionales».

\section{INTRODUCCIÓN}

El pasado 5 de abril, el Tribunal de Justicia dictó, en los asuntos acumulados Pál Aranyosi y Robert Căldăraru, una sentencia trascendental desde la perspectiva de la configuración constitucional del espacio de libertad, seguridad y justicia (ELSJ) de la Unión Europea ${ }^{2}$. En este pronunciamiento de Gran Sala relativo a la ejecución de orden europea de detención y entrega, el Tribunal consagra (y construye) lo que podríamos denominar grosso modo,

2 Sentencia del Tribunal de Justicia de 5 de abril de 2016, Aranyosi y Căldăraru, C-404/15 y C-659/15 PPU, EU:C:2016:198 (en adelante, Sentencia Aranyosi y Căldărăru). Véase su crónica a cargo de Fernando CASTILLO DE LA TORRE y Petra NEMECKOVA en esta Revista de Derecho Comunitario Europeo, núm. 54, 2016, pp. 694-697. 
una excepción de respeto de derechos fundamentales en el funcionamiento de la categoría clave de este espacio, es decir, el reconocimiento mutuo basado en una confianza recíproca entre los Estados miembros.

Por fuerza, esta excepción repercutirá profundamente en el funcionamiento de los instrumentos de cooperación judicial de la Unión, pero, al estar referida al respeto de derechos humanos y a los principios de reconocimiento y confianza mutuos, su importancia se extenderá más allá, hacia las relaciones con los sistemas de protección de estos derechos que se contienen en los órdenes constitucionales y en el Convenio Europeo de Derechos Humanos $(\mathrm{CEDH})$. Recuérdese, sin ir más lejos, el asunto Melloni o la posición determinante que el principio de reconocimiento mutuo revistió en el Dictamen 2/13 concerniente a la adhesión de la Unión al CEDH. Si esta jurisprudencia reduce, neutraliza o, al contrario, activa los controlimiti constitucionales y si, una vez decaída la adhesión, facilita la aplicación de la dispensa Bosphorus o, antes bien, consagra divergencias insalvables entre el Tribunal Europeo de Derechos Humanos (TEDH) y el Tribunal de Justicia (TJUE o Tribunal) son cuestiones centrales de las que, sin embargo, no nos ocuparemos en este trabajo que abordará la cuestión desde el prisma de la protección de los derechos fundamentales en el derecho de la $\mathrm{UE}^{3}$.

Para ello trataré, en primer lugar, de argumentar mediante tres "premisas» que esta jurisprudencia se ha de enmarcar dentro de un tipo específico de problemas de respeto de derechos fundamentales dentro del ELSJ, cuya solución, por tratarse de un problema de fondo, no viene resuelto en el derecho secundario, sino que remite necesariamente a la configuración de los principios de reconocimiento y confianza mutuos en el derecho primario. Esta remisión, sin embargo, no parece abocar a una solución obvia, lo que trataré de mostrar analizando críticamente las dos respuestas, casi antagónicas, que el abogado general y el Tribunal de Justicia elaboran. Finalmente, en el último apartado intentaré justificar, mediante una más clara distinción con el reconocimiento mutuo, que la configuración en derecho primario del principio de confianza mutua debe derivar en la aceptación de una excepción de derechos fundamentales a cargo de los Estados miembros, pero que la emergencia de estos límites «constitucionales» a la confianza mutua no resuelve ni define cuáles son los límites del reconocimiento mutuo dentro del ELSJ.

3 Véase en este mismo volumen, José Manuel CORTÉS MARTÍN, «Sobre la plena vigencia de la presunción de equivalencia (Bosphorus) y su aplicación al principio de reconocimiento mutuo en el espacio de libertad, seguridad y justicia», Revista de Derecho Comunitario Europeo, núm. 55. 


\section{PREMISA PRIMERA: LOS PROBLEMAS DE PROTECCIÓN DE LOS DERECHOS FUNDAMENTALES EN LA COOPERACIÓN JUDICIAL PENAL DE LA UNIÓN}

Decir que el reconocimiento mutuo en el ELSJ y, más concretamente, en la cooperación judicial penal, plantea numerosos problemas de protección de derechos fundamentales es un homenaje a la obviedad. Desde su mismo origen, los tribunales ordinarios, los tribunales constitucionales o el propio TJUE están lidiando con las insuficiencias jurídicas de la manera en la que está resuelta esta cuestión. Naturalmente, el buque insignia de esta cooperación, la orden europea de detención y entrega, ha sido el campo de pruebas más frecuente ${ }^{4}$. La doctrina posiblemente no ha hecho otra cosa que alertar sobre estas insuficiencias y peligros, en una evolución que, acaso, ha pasado del alarmismo primigenio a la actual fe del converso ${ }^{5}$. A mi modo de ver, desde la perspectiva de la protección de derechos fundamentales, todo este acquis litigioso (jurisprudencial y doctrinal) apunta a tres órdenes de problemas que jurídicamente se plantean en términos diversos y sobre los que la jurisprudencia del Tribunal no siempre ha ofrecido una respuesta satisfactoria ${ }^{6}$ :

a) un primer problema, desde la perspectiva de la protección de derechos fundamentales, es qué hacer con los supuestos de violaciones especialmente graves donde se plantea el reconocimiento mutuo. Este es, en mi opinión, un problema de derecho primario y las incertidumbres proceden justamente de ese marco. Es cuestión de determinar hasta dónde llega, no tanto el recono-

4 Decisión Marco 2002/584/JAI del Consejo, de 13 de junio de 2002, relativa a la orden de detención europea y a los procedimientos de entrega entre Estados miembros, DO L 190, de 18 de julio de 2002, p. 1.

5 Entre las críticas originarias es clásica la remisión a Susie ALEGRE y Marisa LEAF, European Arrest Warrant. A solution ahead of its time?, Justice Publication, Londres, 2003. En contraste, véase, recientemente, Valentina FAGGIANI, «El principio de reconocimiento mutuo en el espacio europeo de justicia penal. Elementos para una construcción dogmática», Revista General de Derecho Europeo, núm. 38, 2016, pp. 8894, donde se anticipa a la posición del abogado general en este asunto. Entre los adalides de la posición que rechaza poner límites a esta confianza mutua, pueden citarse magistrados de nuestro Tribunal Constitucional, como Pérez Tremps o Rodríguez Zapata (véase, p.ej., sus votos particulares a la Sentencia del Tribunal Constitucional (Sala 1a) 199/2009, de 28 de septiembre de 2009, BOE núm. 254, de 21.10.2009).

6 Véase Pablo J. MARTÍN RODRÍGUEZ, «The Area of Freedom, Security and Justice and the Information Society. Spanish Report», en J. LAFFRANQUE (ed.), The Area of Freedom, Security And Justice Including Information Society Issues. (Reports of the XXV FIDE Congress), Tartu University Press, Tallín, 2012, vol. 3, pp. 589-599. 
cimiento en sí, cuanto la confianza mutua. Y aquí, centrados en el derecho primario, ya se asoma por qué la cuestión es compleja. Desde sus mismos orígenes (señaladamente en el Consejo Europeo de Tampere), el reconocimiento mutuo basado en la confianza mutua entró en el ELSJ mediante normas de derecho secundario. Esta entrada por la puerta de atrás explica que la comprensión más inmediata de este mecanismo se anclara en sus antecedentes dentro del mercado interior (y que ha llevado a la, para mí impropia, expresión de «libre circulación de resoluciones penales») y apuntase a la equivalencia como fundamento ${ }^{7}$. Inmediatamente surgían los problemas de identificar una equivalencia que era inexistente, en especial porque las posibilidades de alcanzarla mediante la armonización penal procesal y sustantiva se confesaron muy escasas ${ }^{8}$. Aquí es donde la confianza mutua hace entrada como fundamento del reconocimiento alternativo a la equivalencia material y donde progresivamente se van diferenciando el uno de la otra ${ }^{9}$, opción que resulta solo parcialmente consagrada en el derecho originario con el Tratado de Lisboa (arts. 67 y 82 TFUE) ${ }^{10}$. Sin embargo, obsérvese que, en realidad, la cuestión de la equivalencia no desaparece, sino que se traslada del reconocimiento a la confianza: los Estados miembros se deben confianza mutua porque en todos ellos el respeto de los derechos fundamentales no solo existe, sino que es equivalente. Abordado en estos términos, confianza mutua y equivalencia del

7 Un anclaje cuyos defectos fueron claramente advertidos por la doctrina. Por todos, Steve PEERS, «Mutual Recognition and Criminal Law in the European Union: Has the Council Got it Wrong?», Common Market Law Review, vol. 41, núm. 1, 2004, pp. 5-36.

8 Mostrando que el reconocimiento mutuo, como tal, poco podía aportar a la creación de una equivalencia entendida como premisa material (Véase Anne WEYEMBERGH, L’harmonisation des législations: condition de l'espace pénal européen et révélateur de ses tensions, Bruylant, Bruselas, 2004, pp. 336-337.

9 En efecto, la confianza mutua se convertía en un axioma que justamente permitía operar el reconocimiento mutuo en ausencia de sustrato equivalente, es decir, en ausencia de armonización (por todos, Olivier DE SCHUTTER, «La contribution de contrôle juridictionnel à la confiance mutuelle», CRIDH Working Paper 2005/06, pp. $17-22)$.

10 Mientras que el principio del reconocimiento mutuo resulta claramente incorporado, la confianza mutua sólo permanece implícita. La inclusión no es, por implícita, menos clara cuando, como correctamente apunta el abogado general Bot, la competencia atribuida a la Unión para realizar una armonización penal procesal es caracterizada como accesoria al reconocimiento mutuo y no como premisa fáctica (conclusiones del abogado general bot en los asuntos Aranyosi y Căldăraru, C-404/15 y C-659/15 PPU, EU:C:2016:140, punto 96, en adelante conclusiones Bot Aranyosi y Căldăraru). 
respeto de derechos fundamentales quedan indisolublemente ligadas, dejando abierta la cuestión de fondo de cómo lo están, esto es, si la prueba de una falta de equivalencia rompe o no el deber de confianza recíproca entre los Estados.

b) El segundo orden de problemas procede de la instrumentación normativa que ha canalizado esta cooperación bajo el largo reinado del Tratado de Ámsterdam. El tercer pilar, aún mejorando sustancialmente el régimen anterior, establecía un sistema deficiente tanto en sus tipos normativos (fundamentalmente, decisiones marco carentes de eficacia directa según el entonces art. 34 TUE) como en su protección jurisdiccional (el antiguo art. 35 TUE). A estos problemas derivados de la débil instrumentación normativa, el Tribunal, desde la seminal sentencia Pupino, ha reaccionado con una jurisprudencia claramente tendente al refuerzo de la efectividad de estos instrumentos ${ }^{11}-$ lo que, por otra parte, parecía más que necesario ${ }^{12}$ - en la esperanza de que esa política de la Unión no embarrancase en otras instancias judiciales, cuya jurisdicción, a diferencia de la suya, no estaba severamente limitada ${ }^{13}$. La situación no era cómoda, pues recuérdese que, centrados en la seguridad e intensificación de los instrumentos represivos, los Programas de Tampere (1999-2004)

11 De nuevo, por todos, Ester HERLIN-KARNELL, «From Mutual Trust to the Full Effectiveness of EU Law: 10 Years of the European Arrest Warrant», European Law Review, vol. 38, núm. 1, 2013, pp. 79-91, o más reciente, Paul DE HERT, «EU criminal law and fundamental rights», en V. MITSILEGAS et al. (eds.), Research Handbook on EU Criminal Law, Elgar, Cheltenham, 2016, pp. 111-113.

12 Anne WEYEMBERGH et al., "L'effectivité du troisième pilier de l'Union européenne et l'exigence de l'interprétation conforme : la Cour de justice pose ses jalons (note sous l'arrêt Pupino, du 16 juin 2005 de la Cour de justice des Communautés européennes)", Revue trimestrielle des droits de l'homme, vol. 18, núm. 63, 2007, p. 280.

13 Con certeza, el mejor ejemplo son los asuntos SEGI y Gestoras pro Amnistía, donde el TJUE debió hacer una interpretación antiliteral del antiguo art. 35 TUE, para salvar (yo creo que sólo para la instancia), los problemas de violación del derecho a la tutela judicial (Sentencia del Tribunal de Justicia de 27 de febrero de 2007, Gestoras pro Amnistía, C-454/04 P, EU:C:2007:115, apdos. 51-55). Compárese esa solución con las implicaciones de fondo que tenía esa deficiente conformación en el sólido análisis de las Conclusiones del abogado general Mengozzi en los asuntos Gestoras Pro Amnistía y Segi, C-354/04 P y C-355/04 P, EU:C:2006:667, puntos 98-132. Véase, al respecto, Steve PEERS, «Salvation Outside the Church: Judicial Protection in the Third Pillar after the Pupino and SEGI Judgments», CMLR, vol. 44, 2007, pp. 883-929; y Diego J. LIÑÁN NOGUERAS y Pablo J. MARTÍN RODRÍGUEZ, «Reflexiones sobre los derechos fundamentales en la Unión Europea a la luz del Tratado de Lisboa», en A. Badía Martí et al. (dirs.), Derecho internacional y comunitario ante los retos de nuestro tiempo. Homenaje a la Profesora Victoria Abellán Honrubia, Marcial Pons, Barcelona, 2009, vol. II., pp. 1062-1071. 
y La Haya (2005-2009) desatendían, en buena medida, la dimensión de derechos fundamentales y los primeros logros en este ámbito (a través de la armonización procesal penal) solo aparecieron en el Programa de Estocolmo, bajo la égida ya del Tratado de Lisboa ${ }^{14}$. Este Tratado prometía, al final de su período transitorio, un nuevo escenario jurídico con la recuperación de la «plena jurisdicción» del Tribunal y la conversión de todo el acquis del tercer pilar en normas clásicas comunitarias. En 2016, la conversión ni está ni se la espera ${ }^{15}$ y los frutos del recuperado escrutinio de la Comisión, al parecer, se hacen de $\operatorname{rogar}^{16}$.

Lo que interesa destacar es que la opción del Tribunal por la efectividad con ese débil andamiaje jurídico lo han obligado (y lo obligan aún) a solventar con piruetas normativas, no siempre pacíficas ${ }^{17}$, las dificultades más serias

14 Araceli MANGAS MARTÍN y Diego J. LIÑÁN NOGUERAS, Instituciones y derecho de la Unión Europea, Tecnos, Madrid, 9a ed. 2016, pp. 105-106. Acaso, la introducción del procedimiento legislativo ordinario que supuso el Tratado de Lisboa no sea ajena a este giro, con el Programa de Estocolmo, hacia una mayor sensibilidad a los derechos fundamentales que se ha reflejado en los instrumentos de cooperación judicial penal creados con posterioridad.

15 Entre otras razones, por los peligros de regresión en su modificación (véase Anne WEYWMBERGH, Inés ARMADA y Chloé BRIÈRE, "Critical Assessment of the Existing European Arrest Warrant Framework Decision", European Added Value Assessment, 6/2013, Parlamento Europeo, Bruselas, 2014, p. I-7).

16 La conversión ha sido casi inexistente en los instrumentos de cooperación judicial penal y muy reducida en los de armonización penal sustantiva (Araceli MANGAS MARTÍN y Diego J. LIÑ́́N NOGUERAS, op. cit. nota 14, pp. 114-115). Por su parte, si como ha reconocido el propio Consejo Europeo en sus orientaciones estratégicas para el período 2014-2019, «la prioridad general es ahora la transposición sistemática, la aplicación efectiva y la consolidación de los instrumentos jurídicos y de las medidas de política vigentes» (conclusiones del Consejo Europeo de 26 y 27 de junio de 2014, EUCO 79/14, apdo. 3), no parece que la Comisión haya recogido ningún guante: salvo error mío en la búsqueda realizada en su base de datos de incumplimientos, esta no ha abierto ni un solo procedimiento de infracción de una decisión marco desde que recuperó sus competencias como "guardiana de los Tratados».

17 En el asunto Radu, el Tribunal procedió a una reformulación muy restrictiva de las cuestiones remitidas por el órgano a quo, dejándolas reducidas a la cuestión de si el individuo tiene derecho a ser oído antes por la autoridad judicial de emisión de la orden de detención europea; cuestión que, con poca discusión, se debía responder en sentido negativo (Sentencia del Tribunal de Justicia de 29 de enero de 2013, Radu, C-396/11, EU:C:2013:39, apdos. 39-40). Bastante más generosa, la abogada general Sharpston sí atendió a la necesidad de evaluar, desde el punto de vista de los derechos fundamentales, la privación de libertad que la euroorden conlleva en el Estado de 
que, desde la perspectiva del respeto de los derechos fundamentales, se le han planteado. El Tribunal no ha podido escapar a estas dificultades, incluso si, a veces con una inestimable ayuda en la formulación de las preguntas que han contenido los reenvíos prejudiciales, ha mantenido una estrategia de primacía implícita (algo más explícita en Melloni) y un recurso al principio de interpretación conforme igualmente sobrentendido (para evitar tener que habérselas con sus límites) ${ }^{18}$. La reciente sentencia en el asunto $J Z$ muestra que el Tribunal está centrando mejor cuándo la efectividad está realmente en juego, lo que le permite sacar partido de su jurisprudencia Akerberg, pero esto no resuelve la cuestión de fondo ${ }^{19}$. El asunto Lopes Da Silva es suficientemente ilustrativo de la búsqueda de la efectividad, de los límites estructurales de estas normas y de las piruetas a que se ve impelido el Tribunal ${ }^{20}$. Pero, por lo que a nosotros

ejecución, así como a la posibilidad de la autoridad de ejecución de verificar el respeto de los derechos fundamentales en el Estado de emisión (conclusiones de la abogado general Sharpston en el asunto Radu, C-396/1, EU:C:2012:648).

Son muy numerosas las sentencias en las que el Tribunal se ha limitado a indicar la interpretación de la Decisión Marco y la obligación de ejecutar la orden europea que pesa sobre la autoridad judicial sin entrar a determinar si esta puede o no hacerlo si se atienden los límites de esa interpretación conforme. Sobre la relevancia de esta cuestión en el asunto Melloni, véase Pablo J. MARTÍN RODRÍGUEZ, «Crónica de una muerte anunciada: comentario a la Sentencia del Tribunal de Justicia (Gran Sala) de 26 de febrero de 2013, Stefano Melloni, C-399/11», Revista General de Derecho Europeo, núm. 30, 2013, pp. 24-45.

19 En este asunto se planteaba la aplicación del llamado principio de deducción contenido en el art. 26 de la Decisión Marco, según el cual, para evitar incurrir en un doble castigo (bis in idem), se ha de descontar en el Estado de emisión el tiempo de privación de libertad (detención) que el sujeto ha sufrido en el Estado de ejecución y si ciertas medidas de restricción de la libertad distintas de las clásicas de detención o encarcelamiento estaban cubiertas por este principio. El Tribunal fija cuál debe ser la interpretación uniforme de este concepto de «privación de libertad» con soporte en la jurisprudencia del TEDH y sobre la que operaría la interpretación conforme con sus límites; pero, siguiendo al abogado general Campos en sus conclusiones, aplica (sin mencionarla) la jurisprudencia Åkerberg: esa definición es un umbral mínimo, pero nada impide que el Estado de emisión aplique un nivel de protección mayor, esto es, deduzca de la pena a cumplir restricciones de libertad que, según el derecho de la Unión, no alcanzan el umbral de privación de libertad (Sentencia del Tribunal de Justicia de 28 de julio de 2016, JZ, C-294/16 PPU, EU:C:2016:610, apdo. 55).

20 Sentencia del Tribunal de Justicia de 5 de septiembre de 2012, Lopes Da Silva Jorge, C-42/11, EU:C:2012:517. En este caso se plantea la aplicación a nacionales de otros Estados miembros de la posibilidad de que se ejecute la orden de entrega con la condición de que la pena sea cumplida en el Estado de ejecución que recoge la Decisión 
interesa, es más relevante qué ocurre con aquellos casos, no pocos, en los que los Estados, al trasponer la Decisión Marco 2002/584/JAI, han incluido entre los motivos de denegación del reconocimiento una excepción más o menos clara de respeto de derechos fundamentales ${ }^{21}$, porque inmediatamente apunta a los límites de la interpretación conforme: esto es, a la prohibición de una interpretación contra legem y al respeto de los principios generales del derecho de la Unión (que, aparte de los de seguridad jurídica o legalidad penal usualmente mencionados, también incluyen el respeto de derechos fundamentales) ${ }^{22}$.

c) El tercer tipo de problemas en materia de respeto de derechos fundamentales ha procedido, a mi juicio, de lo que podríamos llamar «desajustes regulatorios» entre los sistemas de justicia penal de los Estados miembros. No nos referimos aquí a aquellos desajustes que son un corolario del sistema, es decir, el obstáculo que la confianza mutua sin previa armonización busca justamente superar, sino a otros provocados por opciones normativas del

Marco. Aquí, el tenor de la norma francesa de transposición era claramente opuesto a la interpretación dada por el Tribunal (en puridad, más fundamentada en el estatuto de ciudadanía que en los derechos fundamentales). Por ello, el carácter facultativo del motivo recogido en la Decisión Marco, la vetada eficacia directa y el límite de la interpretación conforme que impide una interpretación contra legem, obligan al Tribunal a tratar de forzar la consecución del resultado, invitando al juez a extraer las consecuencias que su Derecho nacional imponga para las discriminaciones prohibidas.

21 Esta cuestión ya aparecía en el primer Informe de la Comisión basado en el art. 34 de la Decisión Marco del Consejo, de 13 de junio de 2002, relativa a la orden de detención europea y a los procedimientos de entrega entre Estados miembros (versión revisada), 24.1.2006, COM (2006) 8 final, pp. 6-7. Un repaso más reciente puede consultarse en Valsamis MITSILEGAS, "General Report. The Area of Freedom, Security and Justice from Amsterdam to Lisbon. Challenges of Implementation, Constitutionality and Fundamental Rights", en J. LAFFRANQUE (ed.), The Area of Freedom, Security and Justice Including Information Society Issues. (Reports of the XXV FIDE Congress), Tartu University Press, Tallín, 2012, vol. 3, pp. 61-89. La transposición española más reciente (Ley 23/2014, de 20 de noviembre, de Reconocimiento Mutuo de Resoluciones Penales en la Unión Europea (BOE núm. 282, de 21 de noviembre de 2014, p. 12 029) resuelve la cuestión con un enigmático art. 3, según el cual, «La presente Ley se aplicará respetando los derechos y libertades fundamentales y los principios recogidos en la Constitución Española, en el art. 6 del Tratado de la Unión Europea y la Carta de los Derechos Fundamentales de la Unión Europea, y en el Convenio Europeo de Derechos y Libertades Fundamentales del Consejo de Europa de 4 de noviembre de 1950».

22 Ese "prius que legitima la existencia y el desarrollo" del ELSJ del que hablaban las conclusiones del abogado general Cruz en el asunto I.B., C-306/09, EU:C:2010:404, punto 43). 
«legislador europeo» que son arriesgadas, negligentes o, quizás, sencillamente erróneas y cuya transcendencia se amplifica por las debilidades instrumentales que hemos mencionado. Si bien hay claros ejemplos en las normas penales sustantivas, no faltan en las de cooperación judicial, incluida la euroorden. Claramente errónea era la forma en que la Decisión Marco 2002/584/JAI gestionaba los juicios en ausencia en su originario art. 5.1), hasta el punto de que requirió una modificación normativa a cargo de la Decisión Marco 2009/299/ JAI que introdujo el art. 4 bis $^{23}$. Arriesgada era la adopción de unos umbrales penológicos tan bajos para la emisión de una orden europea de entrega, pero no acompañarlos de una exigencia de proporcionalidad puede calificarse de negligente sin peligro de ser tachado de incendiario; pues, de hecho, esta preterición es un problema reconocido por las propias instituciones que solo han sabido articular extra muros una solución poco convincente jurídicamente, si tenemos en mente, no tanto el coste económico, sino las consecuencias que una orden de detención y entrega tiene sobre los derechos fundamentales del individuo concernido ${ }^{24}$. De la misma manera, si la distinción entre motivos facultativos y obligatorios de denegación de la entrega ya es ambigua (no se sabe bien si corresponden al juez o al Estado), la propia caracterización de algunos de ellos como facultativos, verbigracia el art. 4 bis que actualmente regula el reconocimiento de sentencias dictadas en juicios sin comparecencia del acusado, es extraordinariamente problemática desde la perspectiva del respeto de derechos fundamentales ${ }^{25}$.

23 Decisión Marco 2009/299/JAI del Consejo de 26 de febrero de 2009, por la que se modifican las Decisiones Marco 2002/584/JAI, 2005/214/JAI, 2006/783/JAI, 2008/909/JAI y 2008/947/JAI, destinada a reforzar los derechos procesales de las personas y a propiciar la aplicación del principio de reconocimiento mutuo de las resoluciones dictadas a raíz de juicios celebrados sin comparecencia del imputado, DO L 81, de 27 de marzo de 2009, p. 24.

24 Planteado por la práctica judicial, la cuestión ya se hizo hueco en el Informe de la Comisión al Parlamento Europeo y al Consejo sobre la aplicación desde 2007 de la Decisión Marco del Consejo de 13 de junio de 2002 relativa a la orden de detención europea y a los procedimientos de entrega entre Estados miembros, COM (2011) 175 final, pp. 7-9. Había sido asumido por el Consejo en la cuarta ronda de evaluación y derivó en la revisión del Manual europeo de emisión de órdenes europeas (doc. 17195/1/10, 17.12.2010, pp. 14-15). Pero, lo cierto es que, sin modificación normativa, años después sigue siendo un problema (véase Council, «Issues of proportionality and fundamental rights in the context of the operation of the European Arrest Warrant», doc. 9968/14, 20 de mayo 2014).

25 Véase, sin ir más lejos, la reciente Sentencia del Tribunal de Justicia de 24 de mayo de 2016, Dworzecki, C-108/16 PPU, EU:C:2016:346, donde el Tribunal interpreta el 


\section{PREMISA SEGUNDA: UN SUPUESTO DE HECHO PARADIGMÁTICO DE UN PROBLEMA DE FONDO: LAS CONDICIONES DE LOS CENTROS DE DETENCIÓN Y RECLUSIÓN EN LOS ESTADOS MIEMBROS}

Los supuestos de hecho que desembocan en las prejudiciales acumuladas por el Tribunal no son complejos, pero sí apuntan con claridad a un problema de fondo, esto es, al primer tipo de problemas de respeto de derechos fundamentales que hemos mencionado. Ante las autoridades judiciales de Bremen se están desarrollando dos procedimientos de ejecución de órdenes europeas de detención y entrega: la primera, dictada contra el Sr. Pál Aranyosi por un tribunal húngaro, para juzgarlo por la comisión de varios delitos de robo, y la segunda, contra el Sr. Robert Căldărăru, emitida por un tribunal rumano para el cumplimiento de una pena privativa de libertad por conducción de vehículo sin permiso. En ambos casos los interesados se opusieron a la entrega y las peticiones de información del Ministerio Fiscal alemán a las autoridades de emisión sobre en qué centros penitenciarios serían internados no recibieron respuesta ${ }^{26}$.

Dichas peticiones de información venían justificadas por la existencia de pronunciamientos internacionales, en particular, del TEDH, donde las condiciones de reclusión en ambos Estados miembros habían sido consideradas como una violación del art. $3 \mathrm{CEDH}$. En efecto, la excesiva población carcelaria es una situación muy común dentro de los países del Consejo de Europa, incluidos los de la Unión Europea ${ }^{27}$; pero en los casos de Hungría y Rumanía, las constataciones eran poco discutibles y de notable gravedad. Así, el TEDH había dictado, en marzo de 2015, una sentencia piloto contra Hungría en la que establecía la existencia de un problema estructural de su sistema penitenciario, donde la superpoblación carcelaria per se o en conjunción con otras condiciones de detención constituía un tratamiento inhumano o degradante contrario a la dignidad humana y proscrito por la prohibición absoluta del art.

apartado 1 del art. 4 bis para asegurar no sólo una interpretación uniforme (concepto autónomo de derecho de la Unión), sino garantista de que la "citación en persona» o la «notificación oficial por otros medios» se ha producido efectivamente. Semejante garantía tendría poco sentido si un Estado puede, dado su carácter facultativo, sencillamente no contemplar dicha excepción al reconocimiento.

26 Conclusiones Bot Aranyosi y Căldăraru, puntos 27-28.

27 Véase European Committee on Crime Problems, White Paper on Prison Overcrowding, 25 April 2016, Strasbourg, PC-CP (2015) 6 rev 4. 
$3 \mathrm{CEDH}^{28}$. La situación en Rumanía no era menos patente: las condenas por violación del art. $3 \mathrm{CEDH}$ como consecuencia de la sobrepoblación carcelaria se han sucedido una tras otra ${ }^{29}$.

No es, como decimos, un problema confinado a estos dos Estados. Otros miembros han protagonizado también procedimientos piloto por esta cuestión o han sufrido condenas específicas ${ }^{30}$. Y, si se atiende a los informes del Comité Europeo para la Prevención de la Tortura, la conclusión no es muy distinta ${ }^{31}$. No es tampoco un problema nuevo ni desconocido para las instituciones: en su tercer informe sobre la aplicación de la Decisión Marco 2002/584/JAI, la Comisión señalaba este punto expresamente: «Algunas sentencias del Tribunal Europeo de Derechos Humanos han subrayado las deficiencias de determinadas prisiones de la UE. El Tribunal ha declarado que unas condiciones de detención inaceptables (que alcancen un nivel mínimo de gravedad) pueden constituir una violación del art. 3 del Convenio Europeo de Derechos Humanos, incluso aunque no existan pruebas de una intención deliberada de humillar o degradar al detenido »32. En una resolución de 15 de

28 Varga and Others $v$. Hungary, 14097/12, 45135/12, 73712/12, 34001/13, 44055/13 and 64586/13, $\$ \$ 98-100,10$ March 2015. Es interesante advertir que, al momento de dictarse la sentencia, existían pendientes unos 450 casos ante el TEDH incoados contra Hungría y que dicha situación iba acompañada de la inexistencia real de un recurso para las personas afectadas.

29 Véase desde Iacov Stanciu v. Romania, 35972/05, \$187, 24 July 2012 hasta la reciente Eze v. Romania, 80529/13, 21 June 2016, \$\$ 52-59.

30 Así, las sentencias piloto contra Italia (Torreggiani and Others v. Italy, 43517/09, $46882 / 09,55400 / 09,57875 / 09,61535 / 09,35315 / 10$ and $37818 / 10, \$ 94,8$ January 2013) y Bulgaria (Neshkov and Others v. Bulgaria, 36925/10, 21487/12, 72893/12, 73196/12, 77718/12 and 9717/13, 27 January 2015), o las condenas a otros Estados miembros (Vasilescu v. Belgium, 64682/12, 25 November 2014; Canali v. France, 40119/09, 25 April 2013; Mandić and Jović v. Slovenia, 5774/10 and 5985/10, 20 October 2011; Štrucl and others v. Slovenia, 5903/10, 6003/10 and 6544/10, 20 October 2011; Karalevičius v. Lithuania, 53254/99, 7 April 2005; Sikorski v. Poland, 17599/05, 22 October 2009).

31 Véase sus estándares en Living space per prisoner in prison establishments: CPT standards, Strasbourg, 15.12.2015, doc. CPT/Inf (2015) 44.

32 Informe de la Comisión al Parlamento Europeo y al Consejo sobre la aplicación desde 2007 de la Decisión Marco del Consejo de 13 de junio de 2002 relativa a la orden de detención europea y a los procedimientos de entrega entre Estados miembros, Bruselas, 11.4.2011, COM(2011) 175 final, p. 7. Continuaba el informe, afirmando: «Es evidente que la Directiva [sic] Marco del Consejo relativa a la ODE (que en su art. 1, apartado 3, establece que los Estados miembros deben respetar los derechos fundamentales y los principios jurídicos fundamentales, incluido el art. 3 del Convenio 
diciembre de 2011, el Parlamento Europeo insistía sobre esta cuestión hasta el punto de sugerir una actuación normativa de la UE al respecto y, lo que a estos efectos importa, como veremos, alertaba sobre las consecuencias que dicha situación desplegaba socavando la necesaria confianza mutua entre los Estados miembros ${ }^{33}$.

Ante la seriedad de las cuestiones jurídicas en juego, el Tribunal Superior Regional Civil y Penal de Bremen (Hanseatisches Oberlandesgericht in Bremen) decide activar el reenvío prejudicial, planteando para ambos casos dos cuestiones idénticas: la primera, sobre si tales condiciones constituyen un motivo de denegación de la entrega o, al menos, si justifican condicionarla a la prestación de garantías por parte del órgano emisor de que los derechos fundamentales y principios jurídicos del art. 6 TUE serán respetados ${ }^{34}$; y, la segunda, sobre si se puede deducir de la decisión marco que la autoridad emisora está capacitada para ofrecer tales garantías con independencia de la distribución competencial interna ${ }^{35}$. Aunque tramitados por procedimientos diferentes (acelerado y de urgencia), pues solo uno de los interesados se encontraba privado de libertad a espera de la resolución del procedimiento de entrega, el Tribunal procede a la acumulación de asuntos y a su asignación a la Gran Sala.

Estas prejudiciales encierran, como se puede observar, una cuestión endemoniada. El tema de si el reconocimiento mutuo de resoluciones penales en el marco del espacio de libertad, seguridad y justicia podía sujetarse a exigencias de respeto de derechos fundamentales en el Estado de emisión no solo no había sido resuelto por el Tribunal, sino que las señales normativas

Europeo de Derechos Humanos) no ordena la entrega cuando la autoridad judicial responsable de la ejecución, teniendo en cuenta todas las circunstancias del caso, estima que la entrega vulneraría los derechos fundamentales de la persona buscada como consecuencia de unas condiciones de detención inaceptables» (ibid, cursiva añadida).

33 Resolución del Parlamento Europeo, de 15 de diciembre de 2011, sobre las Condiciones de Privación de Libertad en la UE (2011/2897(RSP), DO C 168, de 14 de junio de 2013, p. 82, considerandos B, D y E.

34 La normativa alemana de transposición contiene una disposición según la cual «la asistencia judicial será ilícita si es contraria a los principios consagrados en el art. 6 [TUE]».

35 En una fase anterior, el Ministerio Fiscal de Bremen solicitó información a las autoridades de emisión sobre en qué establecimiento penitenciario serían encarcelados los sujetos, recibiendo en ambos casos respuestas negativas. Mientras que la autoridad judicial rumana decía no estar en condiciones de indicarlo, el Ministerio Fiscal húngaro respondió que dicha cuestión pertenecía a la competencia de las autoridades judiciales húngaras (Sentencia Aranyosi, apdos. 36 y 56). 
o jurisprudenciales y las aportaciones doctrinales eran extraordinariamente confusas $^{36}$. El carácter directo de las preguntas y, sobre todo, del supuesto de hecho impedían que el Tribunal resolviese por vías alternativas eludiendo la cuestión central. La trascendencia, además, de la jurisprudencia que se sentase en este asunto resultaba palmario: estaban en juego el funcionamiento mismo del espacio judicial penal europeo y el respeto de los propios fundamentos y valores de la construcción jurídica de la Unión y de sus Estados miembros.

\section{PREMISA TERCERA: EL INCIERTO SUSTRATO JURÍDICO DE LA CUESTIÓN EN DERECHO SECUNDARIO}

Partamos de una primera constatación. Lo cierto es que la cuestión del respeto de los derechos fundamentales en materia de euroórdenes está resuelta de forma, cuando menos, confusa en la Decisión Marco 2002/584/JAI. En efecto, su art. 1.3 proclama apodícticamente que «La presente Decisión Marco no podrá tener por efecto el de modificar la obligación de respetar los derechos fundamentales y los principios jurídicos fundamentales consagrados en el art. 6 del Tratado de la Unión Europea». Sin embargo, entre los motivos de denegación y de sujeción de la entrega a condición, tal excepción no se encuentra recogida expresamente con carácter general, aunque sí cabría reconducir ciertas de estas causas a los derechos fundamentales (desde aquellas referidas al ne bis in idem a los casos de penas a perpetuidad o juicios en ausencia) ${ }^{37}$.

De hecho, el mismo tenor de las garantías otorgadas a los sujetos entregados ofrecería ciertas dudas sobre la existencia de un parámetro europeo por la continua remisión al Derecho interno de los Estados y un énfasis mayor en la no frustración de la entrega que en el respeto de los derechos fundamentales (quizá el más claro ejemplo es la regulación del mantenimiento en detención

36 La variable posición de los Estados intervinientes en el procedimiento es ilustrativa de ello. Sentencia y conclusiones son parcas en esta interesante información que se puede consultar en Henning BANG FUGLSANG MADSEN SØRENSEN, «Mutual trust - blind trust or general trust with exceptions? The CJEU hears key cases on the European Arrest Warrant», http://www.eulawanalysis.blogspot.com, acceso 13.10.2016. Obsérvese que el mandato del art. 1.3 resuelve claramente que los Estados (como la propia Decisión Marco) deben respetar los derechos fundamentales cuando le dan aplicación, es decir, cuando emiten o reconocen una orden europea, pero no resuelve per se la cuestión de si dentro de esa obligación se encuentra la de rechazar la entrega basado en que otro Estado los ha violado. De ahí que esa cuestión debiera encontrar su solución en los motivos de denegación del reconocimiento de la resolución penal. 
del sujeto en el art. $\left.12^{38}\right)$. El recurso a los considerandos preambulares no resultaba más concluyente, como lo prueba la interpretación que les había dado la doctrina, antes bien complicaba la cuestión ${ }^{39}$.

Por su parte, los restantes instrumentos de la cooperación judicial penal creados reproducen, no sin cierto fundamento, esta indefinición ${ }^{40}$ : compartiendo todas el mandato del respeto de los derechos fundamentales, la mayoría reproduce en un mayor o menor porcentaje la solución de la Decisión

38 A pesar de la remisión al derecho interno, el Tribunal ha debido interpretar la necesidad de que la aplicación de esa disposición respete el art. 6 de la Carta y la jurisprudencia del TEDH relativa al art. $5 \mathrm{CEDH}$ sobre la prohibición de una duración excesiva en caso de inobservancia de los plazos para la decisión final sobre entrega en la Sentencia de 16 de julio de 2015, Lanigan, C-237/15 PPU, EU:C:2015:474, apdos. 53-60.

39 Mientras que el considerando décimo incide en la importancia del grado elevado de confianza entre los Estados para afirmar que sólo podrá suspenderse en aplicación del mecanismo contemplado en el art. 7 TUE para la violación grave y persistente de los principios recogidos en el entonces art. 6 TUE, el duodécimo apunta que nada en la decisión podrá impedir que un Estado rechace la entrega «cuando existan razones objetivas para suponer que dicha orden de detención europea ha sido dictada con fines de persecución o sanción a una persona por razón de sexo, raza, religión, origen étnico, nacionalidad, lengua, opiniones políticas u orientación sexual, o que la situación de dicha persona pueda quedar perjudicada por cualquiera de estas razones». Más aún, este párrafo afirma que «no impedirá a ningún Estado miembro aplicar sus normas constitucionales relativas al respeto del derecho a un proceso equitativo, la libertad de asociación, libertad de prensa y libertad de expresión en los demás medios». Por si fuera poco, por su tenor literal, el considerando 13, según el cual «nadie podrá ser devuelto, expulsado o extraditado a un Estado en el que corra un grave riesgo de ser sometido a la pena de muerte, a tortura o a otras penas o tratos inhumanos o degradantes», deja abierta la puerta a una interpretación a contrario. Véase toda esta cuestión en Steve PEERS, EU Justice and Home Affairs Law, OUP, Oxford, $4^{\mathrm{a}}$ ed. 2016, vol. II, pp. 86-101.

40 Hasta cierto punto esta divergencia es lógica, pues la incidencia que la protección de los derechos fundamentales tiene sobre los instrumentos de cooperación judicial penal es extremadamente diversa. Piénsese el impacto tan divergente que tiene sobre derechos fundamentales un instrumento destinado a la persecución y punición del individuo (p.ej., la euroorden) o uno tendente a su reinserción o menor restricción de sus derechos (p.ej., el reconocimiento de una resolución que establece una medida alternativa a la privación de libertad). En este sentido, John R. SPENCER, «EU Criminal Law - the Present and the Future?», en A. ARNULL et al. (eds.), A Constitutional Order of States? Essays in EU Law in Honour of Alan Dashwood, Hart Publishing, Oxford, 2010, pp. 355-357. 
Marco 2002/584/JAI, pero existen algunas que recogen una explícita excepción (en sentido lato) de respeto de los derechos humanos entre los motivos de denegación, como ocurre con el art. 20.3 de la Decisión Marco 2005/214/ JAI, sobre Reconocimiento de Sanciones Pecuniarias ${ }^{41}$ o el art. 11.1.f) de la más reciente Directiva 2014/41/CE' sobre la Orden Europea de Investigación en Materia Penal ${ }^{42}$.

Ante esta situación del derecho derivado, la jurisprudencia tampoco había mostrado una dirección clara. De un lado, es cierto que el Tribunal había admitido en la sentencia $N$. S. una excepción similar en el marco del funcionamiento del sistema de Dublín y los paralelismos pesaban (una sentencia poco cuestionable del TEDH y la afectación del mismo derecho ${ }^{43}$, pero, sin embargo, su extrapolación a la cooperación judicial penal no era, ni de lejos, tan obvia. Como sabemos, en la sentencia Melloni, el Tribunal parecía descartar que tal excepción existiese más allá de los motivos de denegación o condicionamiento de la entrega recogidos en la Decisión Marco que, al respecto, era perfectamente compatible con la Carta de derechos fundamentales de la Unión (Carta, en adelante). A pesar de que es obvio que el asunto Melloni discurría por territorios distintos — esencialmente, los de la oponibilidad del estándar nacional-, la consideración de la Decisión Marco como compatible con la Carta tenía mayor peso, pues en caso de ausencia de margen para el Estado concedido por el derecho de la Unión (una armonización la llama el Tribunal), la Carta fijaba un umbral máximo de protección, esto es, una protección uniforme que no puede ser cuestionada sin contravenir la efecti-

41 Decisión Marco 2005/214/JAI del Consejo, de 24 de febrero de 2005, relativa a la aplicación del principio de reconocimiento mutuo de sanciones pecuniarias (DO L 76, de 22 de marzo de 2005, p. 16).

42 Directiva 2014/41/UE del Parlamento Europeo y del Consejo, de 3 de abril de 2014, relativa a la orden europea de investigación en materia penal (DO L 130, de 1 de mayo de 2014, p. 1).

43 Sentencia del Tribunal de Justicia de 21 de diciembre de 2011, N.S., C-411/10 y C-493/10, EU:C:2011:865. En una sentencia posterior, el Tribunal había perfilado que el individuo solo podía cuestionar la aplicación del régimen de Dublín si «invocaba deficiencias sistemáticas en procedimiento de asilo y en las condiciones de los solicitantes en el Estado de destino que constituyan motivos serios y acreditados para creer que dicho solicitante correrá un riesgo real de ser sometido a tratos inhumanos o degradantes, en el sentido del art. 4 de la Carta» (Sentencia del Tribunal de Justicia de 10 de diciembre de 2013, Abdullahi, C-394/12, EU:C:2013:813, apdo. 62). Se ha interpretado esta sentencia como la exigencia de un control de riesgo concreto adicional a la exigencia de uno general que establezca las deficiencias sistemáticas (Valentina FAGGIANI, op. cit., nota 5, p. 93). 
vidad de la Decisión Marco y contravenir los principios de confianza y reconocimiento mutuo ${ }^{44}$. Pero era en el Dictamen $2 / 13$, donde el Tribunal había enunciado con más claridad la resistencia del principio de confianza mutua del ELSJ a un escrutinio severo desde la perspectiva de los derechos humanos, abriendo incluso la posibilidad de una respuesta negativa. En efecto, en el dictamen, el Tribunal afirma que dicho principio de confianza mutua obliga a los Estados miembros a presumir que los demás respetan los derechos fundamentales reconocidos en el derecho de la Unión, pero, sobre todo, que «les está vedado no solo exigir a otro Estado miembro un nivel de protección nacional de los derechos fundamentales superior al garantizado por el derecho de la Unión, sino incluso verificar, salvo en supuestos excepcionales, si ese otro Estado miembro ha respetado efectivamente, en un caso concreto, los derechos fundamentales garantizados por la Unión» ${ }^{45}$.

La clave desde la perspectiva del derecho de la Unión es, pues, determinar cuáles son esos «supuestos excepcionales» en los que la confianza mutua decae emergiendo la obligación de verificar el respeto de derechos fundamentales en otro Estado miembro (y en qué medida concurrían en el caso). Pero lo que en este momento es preciso hacer notar es que, en ausencia de una solución de esa cuestión establecida en el derecho derivado, la respuesta por fuerza remite al derecho originario, esto es, a la relación que los Tratados trazan entre confianza mutua y respeto de derechos fundamentales y allí, como ya hemos señalado, los asideros jurídicos tampoco son numerosos, lo que inmediatamente significa que esta tarea ha sido remitida al juez comunitario y en este

44 Sentencia del Tribunal de Justicia de 26 de febrero de 2013, Melloni, C-399/11, EU:C:2013:107, apdos. 60-63. Naturalmente, el tema de fondo aquí es la interpretación que el Tribunal de Justicia le dio al art. 53 de la Carta, desproveyéndola de sustancia (Alexandros KARGOPOULOS, «Fundamental rights, national identity and EU criminal law», en V. MITSILEGAS et al. (eds.), Research Handbook on EU Criminal Law, Elgar, Cheltenham, 2016, p. 133), con la doble consecuencia de atraer los límites constitucionales al impedir todo espacio constitucional más protector frente a la unidad, efectividad y primacía del derecho de la Unión, (Aida TORRES PÉREZ, «Melloni in Three Acts: From Dialogue to Monologue», European Constitutional Law Review, vol. 10, 2014, pp. 308-331) y de colocar su gestión en parámetros de confrontación con importación del conflicto constitucional interno (Leonard BESSELINK, «The Parameters of Constitutional Conflict after Melloni», European Law Review, vol. 39, 2014, pp. 531-552).

45 Dictamen 2/13 del Tribunal de Justicia de 18 de diciembre de 2014, EU:C:2014:2454, apdo. 192, cursiva añadida. Sobre esta cuestión, véase Manuel LÓPEZ ESCUDERO, «Contrôle externe et confiance mutuelle : deux éléments clés du raisonnement de la CJUE dans l'avis 2/13», Revue des affaires européennes, núm. 1, 2015, pp. 93-107. 
sentido más que encontrar una solución, el Tribunal se ve ante la necesidad de «construir» esa solución. A mi modo de ver, así es como han de entenderse tanto la posición del abogado general como del Tribunal, muy dispares entre sí y, al mismo tiempo, justifica que nos detengamos a ver ambas.

\section{LA SOLUCIÓN PROPUESTA POR EL ABOGADO GENERAL: RECHAZO DE LA EXCEPCIÓN Y ALGO MÁS QUE PROPORCIONALIDAD}

La forma en la que el abogado general Bot aborda la cuestión ha sido criticada por la doctrina que, por el contrario, ha elogiado la solución ofrecida por el Tribunal ${ }^{46}$. Unas consideraciones preliminares, donde se rechaza que la solución $N$. S. adoptada en el sistema de asilo sea extrapolable al marco de la euroorden, nos adelantan en parte el contenido y el talante de su argumentación ${ }^{47}$. Esta es relativamente sencilla: su punto de partida es la negación de que la «excepción de derechos humanos» haya sido acogida en el sistema de la euroorden basado en tres razones principales: 1) por su tenor, no puede interpretarse que el art. 1.3 de la Decisión Marco ampare un motivo autónomo de denegación de la ejecución de una orden europea ${ }^{48}$;2) que dicho sistema solo puede suspenderse siguiendo el procedimiento del art. 7 TUE como indica el

46 Véase Gabriele ASTA, «La sentenza della Corte di Lussemburgo sul caso Aranyosi e Căldăraru: una (difficile) coesistenza tra tutela dei diritti fondamentali e mandato di arresto europeo", Osservatorio Costituzionale, fasc. 2/2016, p. 7; y, especialmente, Szilárd GÁSPÁR-SZILÁGY, "Joined Cases Aranyosi and Căldăraru: Converging Human Rights Standards, Mutual Trust and a New Ground for Postponing a European Arrest Warrant", European Journal of Crime, Criminal Law and Criminal Justice, vol. 24, 2016, pp. 203-206. Menos críticas se muestran Emmanuelle BRIBOSIA y Anne WEYEMBERGH, «Arrêt Aranyosi et Căldăraru: imposition de certaines limites à la confiance mutuelle dans la coopération judiciaire pénale», Journal de droit européen, núm. 6, 2016, pp. 225-227.

47 Ciertos argumentos literales más débiles y un énfasis quizá excesivo en una lógica consecuencialista, no pueden ocultar la fuerza de argumento central: aún perteneciendo ambos al ELSJ, el régimen de asilo y de la orden europea «responden a objetivos diferentes y cada uno tiene sus propias características, estructuradas en torno a normas y principios específicos»: básicamente ofrecer un espacio común de protección internacional, el primero, y garantizar un espacio común de persecución y represión de la delincuencia, la segunda (conclusiones Bot Aranyosi y Căldăraru, puntos 39-65, citado punto. 49). En contra, Szilárd GÁSPÁR-SZILÁGY, op. cit. nota 46, p. 204.

48 Conclusiones Bot Aranyosi y Căldăraru, puntos 72-78. 
considerando décimo de la Decisión Marco (cosa que debería haber hecho el Consejo) ${ }^{49}$, y 3) que los principios rectores del sistema (reconocimiento mutuo y confianza mutua) militan en contra de dicha excepción.

Hay pocas cosas discutibles en ese razonamiento del abogado general. En efecto, el Tribunal ha interpretado, sin dejar lugar a dudas, que una orden europea solo puede dejar de reconocerse por los motivos expresamente recogidos en los arts. 3 a 4 bis y ahí la excepción no tiene cabida ${ }^{50}$. Por su parte, el principio de confianza mutua (con el contenido que el Tribunal le ha dado en la sentencia Jeremy $F$. y el Dictamen 2/13) se vería menoscabado de admitirse tal excepción e, impedido el reconocimiento mutuo, el sistema de entrega y su consecuente objetivo de la persecución del delito, colapsarían. Atendido el número de Estados miembros que registran un problema de sobrepoblación carcelaria generalizada, el efecto sería introducir una excepción sistemática ${ }^{51}$, desembocando, dado el principio de territorialidad del Derecho penal, en la impunidad (pues el sujeto que no es entregado no puede ser juzgado por el Estado donde permanece) y/o en severas disfunciones de los sistemas penitenciarios nacionales (en caso de que, tras su juicio, se ejecutase la pena en dicho Estado).

Frente a la primera parte, más sólida, la segunda línea argumentativa del abogado general es poco convincente, sustantiva y procedimentalmente. Bot liga las condiciones de detención y reclusión al principio de individualización de la pena y este al principio de proporcionalidad del derecho de la Unión, para tratar de atajar el problema en la fase de emisión de la euroorden: la autoridad judicial no debería emitirla, pues sería desproporcionada ${ }^{52}$. Siendo interesante y pertinente este enfoque en la emisión, la solución propuesta pierde fuerza, ya que, llegado el caso, la desproporcionalidad de una orden

49 Conclusiones Bot Aranyosi y Căldăraru, puntos 79-93. Lo destacado es que Bot, de nuevo con extrema literalidad (incluido la relevancia de que el considerando 13 hable de "extraditado" pero no «entregado») extrae de ello que el legislador de la Unión ha querido justamente sustraer al juez interno de esta cuestión.

50 Conclusiones Bot Aranyosi y Căldăraru, puntos 102-105 o 117 (en referencia a Melloni).

51 Conclusiones Bot Aranyosi y Căldăraru, punto 123. No le falta razón al abogado general, la jurisprudencia N.S. ha hecho que Grecia esté de facto fuera del sistema Dublín (véase la Recomendación (UE) 2016/193 de la Comisión, de 10 de febrero de 2016, dirigida a la República Helénica sobre las medidas urgentes que Grecia debe adoptar con vistas a la reanudación de los traslados en virtud del Reglamento (UE) 604/2013 del Parlamento Europeo y del Consejo, DO L 38, de 13 de febrero de 2016, p. 9).

52 Conclusiones Bot Aranyosi y Căldăraru, puntos 137-155. 
emitida puede suscitarse ante la autoridad judicial de ejecución ${ }^{53}$ y esta, una vez obtenida la información de las autoridades competentes de ambos Esta$\operatorname{dos}^{54}$, debería negarse a ejecutarla, eventualmente con ayuda del TJUE por vía prejudicial $^{55}$.

Se puede sospechar que el abogado general acuda al principio de proporcionalidad (y no sencillamente al art. 4 de la Carta) por los problemas de preterición que hemos mencionado, pero, aunque en términos de principios, el punto de llegada sea el mismo (admisión de una excepción) ${ }^{56}$, el resultado es bien distinto, pues la excepción va de la mano de la obligación que pesaría sobre la autoridad de emisión de aplicar la Decisión Marco conforme al principio de proporcionalidad con primacía sobre la legislación penal estatal en una afirmación con consecuencias de un calado, evidentemente, extraordinario y no sé si enteramente sopesadas ${ }^{57}$.

53 Conclusiones Bot Aranyosi y Căldăraru, punto 160. De hecho, atendida la jurisprudencia Radu (supra nota 17), es difícil que el individuo pudiera activar este control antes de la emisión de la orden: la alegación de este incumplimiento de la proporcionalidad ante la autoridad de emisión sería necesariamente paralelo al desarrollo del procedimiento ante la autoridad de ejecución.

54 Conclusiones Bot Aranyosi y Căldăraru, puntos 167-168.

55 Aunque de forma ciertamente confusa, creo que es lo que está afirmando el abogado general (conclusiones Bot Aranyosi y Căldăraru, puntos 163 y 172).

56 En este sentido, Gabriele ASTA, op. cit. nota 46, p. 7; Szilárd GÁSPÁR-SZILÁGY, op. cit. nota 46, p. 7.

57 Conclusiones Bot Aranyosi y Căldăraru, punto 173. Es esta una afirmación de enorme calado, pues, aunque como hemos mencionado, el Tribunal mantiene en una nebulosa la afirmación de esta primacía, el abogado general cruza claramente el umbral de la interpretación conforme para postular una invocabilidad de exclusión, en lo que se supone que sería un retorno de la eficacia directa vetada por el derecho originario (antiguo art. 34 TUE) al prístino reducto de la invocabilidad de sustitución. Lo cierto es que las consecuencias de una afirmación de este calibre no son claras. Afirmar esta invocabilidad de exclusión (inaplicación de la norma interna contraria) sin una clara invocabilidad de sustitución podría provocar enormes consecuencias desde la perspectiva del propio funcionamiento del espacio de cooperación judicial penal. Piénsese en las consecuencias de la lógica de la invocabilidad de exclusión (sin sustitución) respecto de cualquier motivo de denegación del reconocimiento o, con mayor claridad, sobre los instrumentos de armonización penal sustantiva, en los que esta primacía desembocaría por necesidad en la despenalización, con una reversión de la jurisprudencia Advocaten voor der Wereld. Otra cosa bien distinta sería explorar la eficacia directa y la primacía de los principios generales del derecho de la Unión (no de las decisiones marco), donde el Tribunal podría encontrar herramientas de mayor solidez para gestionar la debilidad instrumental de aquellas. 
En el haber de estas conclusiones, creo, está poner el acento sobre la autoridad de emisión en la aplicación del principio de proporcionalidad, sobre las conexiones que el supuesto de hecho tiene con el art. 7 TUE, pero también con la inacción legislativa de las instituciones, y sobre la necesidad de atender a los objetivos y principios del sistema de la euroorden para interpretar los derechos fundamentales en la clásica aproximación funcional. En el debe, y no es poco, hay un excesivo peso de argumentos literales (que arruinarían la propia solución propuesta, pues la proporcionalidad tampoco está recogida como motivo de inejecución de una orden europea $)^{58}$ y, sobre todo, una magrísima ponderación de la centralidad del derecho fundamental en juego, la prohibición del trato inhumano o degradante (empeorado por un hilarante error de traducción en la versión española en el punto 143). El Tribunal opta por un razonamiento opuesto.

\section{LA SOLUCIÓN DEL TRIBUNAL: LA ACEPTACIÓN DE UNA «EXCEPCIÓN» SEVERAMENTE PROCEDIMENTALIZADA PERO DE PERFILES INCIERTOS}

En su sentencia el Tribunal, redefiniendo el alcance de las preguntas para centrarlas en el caso concreto, da una respuesta conjunta. Partiendo, como no podía ser menos, del objetivo perseguido por la euroorden dentro del ELSJ, retoma la centralidad de los principios de reconocimiento mutuo y confianza mutua en el derecho de la Unión, de manera que una autoridad judicial solo podrá negarse a la ejecución por los motivos establecidos en los arts. 3 a 4 bis de la Decisión Marco ${ }^{59}$; y recalca que el mecanismo en sí solo podrá suspenderse en caso de violación grave y sistemática de los valores del art. 2 TUE y por el procedimiento establecido en el art. $7 \mathrm{TUE}^{60}$.

Sin embargo, el Tribunal señala que los principios de reconocimiento y confianza mutuos pueden limitarse en "casos excepcionales» ${ }^{61}$ y aquí es donde, atendido el art. 1.3 de la Decisión Marco y el 51 de la Carta, procede a la ponderar la importancia del derecho en cuestión: la prohibición de la tortura y los tratos inhumanos o degradantes. Se trata de una prohibición que, indisociable de la dignidad humana recogida igualmente en el art. 1 de la Carta,

\footnotetext{
58 Compartido por Szilárd GÁSPÁR-SZILÁGY, op. cit. nota 46, p. 7.

59 Sentencia Aranyosi y Căldăraru, apdos. 77-80.

60 Sentencia Aranyosi y Căldăraru, apdo. 81.

61 Sentencia Aranyosi y Căldăraru, apdo. 82.
} 
representa un «valor fundamental de la Unión y de sus Estados miembros» y, por esta razón, se encuentra recogida, tanto en el art. 4 de la Carta como en el art. $3 \mathrm{CEDH}$ con el que se corresponde, en términos absolutos e inderogables en toda circunstancia ${ }^{62}$. Por eso, cuando la autoridad de ejecución "disponga de elementos que acrediten un riesgo real de que se inflija un trato inhumano o degradante a las personas encarceladas en el Estado miembro emisor, con arreglo a la norma de protección de los derechos fundamentales garantizada por el derecho de la Unión y, en particular, por el art. 4 de la Carta [...], dicha autoridad deberá apreciar la existencia de ese riesgo a la hora de pronunciarse sobre la entrega [...], porque la ejecución de dicha orden no puede dar lugar a que se trate de forma inhumana o degradante a esa persona ${ }^{63}$.

Para apreciar ese riesgo real, el Tribunal retoma, sin citarla ${ }^{64}$, el espíritu de la jurisprudencia $N$. S.-Abdullahi, pero articulando una excepción mejor definida sustantiva y, sobre todo, procedimentalmente que la doctrina ha descrito como un doble test o control general y concreto ${ }^{65}$. La autoridad judicial deberá, primero, basarse en «elementos objetivos, fiables, precisos y debidamente actualizados [...] que demuestren la existencia de deficiencias sistémicas o generalizadas que afecten a ciertos grupos de personas o a ciertos centros de reclusión", los cuales "pueden proceder en particular de resoluciones judiciales internacionales, como las sentencias del TEDH, de resoluciones judiciales del Estado miembro emisor o de decisiones, informes u otros documentos elaborados por los órganos del Consejo de Europa o del sistema de las Naciones Unidas" ${ }^{66}$. Aunque se ha llamado la atención sobre la ausencia de referencias a fuentes privadas ${ }^{67}$, creo que, mencionando a título ejemplificativo esos

62 Sentencia Aranyosi y Căldăraru, apdos. 83-87.

63 Sentencia Aranyosi y Căldăraru, apdo. 88. Bribosia y Weyembergh observan que, al convertirlo en una obligación, el Tribunal va más allá de la Directiva sobre la orden europea de investigación que sólo prevé un motivo de denegación facultativo (Emmanuelle BRIBOSIA y Anne WEYEMBERGH, op. cit. nota 46, p. 226). Por el contrario, Asta duda de que haya sido concebido como una obligación del juez y no una mera facultad y, aquí justamente encuentra una diferencia clara con la jurisprudencia N.S. (Gabriele ASTA, op. cit. nota 46, p. 6).

64 Bien sea, como dicen Bribosia y Weyembergh, como una concesión a la posición opuesta del abogado general, bien por las diferencias de razonamiento al añadir el test de control concreto (Emmanuelle BRIBOSIA y Anne WEYEMBERGH, op. cit. nota 46, p. 227).

65 Gabriele ASTA, op. cit. nota 46, pp. 5-6; Szilárd GÁSPÁR-SZILÁGY, op. cit. nota 46, p. 207; Emmanuelle BRIBOSIA y Anne WEYEMBERGH, op. cit. nota 46, p. 226.

66 Sentencia Aranyosi y Căldăraru, apdo. 89, cursiva añadida.

67 Szilárd GÁSPÁR-SZILÁGY, op. cit. nota 46, p. 214. 
referentes, el Tribunal busca dos objetivos: primero, particularmente obvio y realmente nunca discutido, garantizar que quedan excluidos temores basados en meras conjeturas, acusaciones vagas o sospechas generales: las deficiencias sistémicas deben estar suficientemente acreditadas ${ }^{68} ; \mathrm{y}$, segundo, al privilegiar las fuentes oficiales, el Tribunal se asegura de que tales apreciaciones (que, para existir, precisarán de un período temporal no pequeño como mencionó Hungría en la vista), se realizan de conformidad con estándares normativos consolidados o internacionales y, en consecuencia, estarán más próximos al estándar del derecho de la Unión. Es, por ello, lógico que entre ellas se encuentren, en primer lugar, las sentencias del TEDH, dada la conexión del CEDH con el estándar mínimo de la Carta ${ }^{69}$.

Al Tribunal, sin embargo, le preocupa menos insistir en el carácter sistémico (que parece flexibilizar al admitir que puede estar referido a un grupo de personas o a ciertos centros ${ }^{70}$ ) porque la afirmación general de estas deficiencias sistémicas no es presupuesto suficiente para que opere la excepción ${ }^{71}$. El Tribunal añade no solo un control adicional exigiendo que quede acreditado que el sujeto concreto corre un riesgo real de sufrir un trato inhumano o degradante $^{72}$, sino que utiliza este doble test para introducir unas exigencias procedimentales que embridan la decisión de rechazar la entrega (que ya no podrá ser automática) y donde desliza aspectos que pueden ser relevantes.

68 Es, por ejemplo, el caso de nuestro Tribunal Constitucional (STC 199/2009, de 28 de septiembre de 2009, FJ 2).

69 Sentencia Aranyosi y Căldăraru, apdo. 90. El Tribunal de Justicia le hace un guiño al TEDH reproduciendo, a renglón seguido y no cuando determinó el alcance del art. 4 de la Carta, una sentencia piloto de este donde se determina el estándar aplicable en el marco del art. 3 CEDH. La señal, como casi siempre, es ambivalente: en lugar de usar una sentencia referida a Hungría o Rumanía, cita el asunto Torreggiani y otros/Italia. Así, una sentencia piloto del TEDH es el indicio privilegiado y, aunque es obvio que cubriría sobradamente lo exigido por el Tribunal de Justicia, este se guarda de dejar traslucir que sea automático.

70 En este sentido Gabriele ASTA, op. cit. nota 46, p. 10. La flexibilización es importante, en la medida en que dará cabida a especificaciones en relación con determinados grupos como enfermos mentales, detenidos, condenados a penas de perpetuidad o menores, entre otros, en los que la aplicación de esta excepción puede ampliarse, más allá del respeto de los estándares penitenciarios acordados en el Consejo de Europa. La consulta de la base de datos del Comité (http://hudoc.cpt.coe.int/) se confesará especialmente útil en este sentido.

71 Sentencia Aranyosi y Căldăraru, apdo. 91.

72 Sentencia Aranyosi y Căldăraru, apdos. 92-94. 
Así, cuando el juez de ejecución se encuentre ante una deficiencia sistémica acreditada deberá recabar de la autoridad de emisión toda la información complementaria sobre las condiciones de reclusión previstas para esa persona $^{73}$, incluida la existencia de procedimientos o mecanismos nacionales o internacionales de control de tales condiciones ${ }^{74}$. La autoridad de emisión estará obligada a remitirla, eventualmente con la asistencia de sus autoridades centrales, salvándose así cualquier dificultad que pudiera derivarse de la distribución competencial existente en el Estado ${ }^{75}$. Ahora bien, si a la luz de tales informaciones, el juez constata que existe ese riesgo real concreto, no podrá denegar la entrega, sino solo aplazar la decisión, lo que justifica el Tribunal con un recurso, muy forzado a mi juicio, a la sentencia Lanigan ${ }^{76}$. En la medida en que esta suspensión puede conllevar que el sujeto siga detenido a la espera de la decisión final, el Tribunal recuerda, ahora sí con propiedad, la jurisprudencia Lanigan para que dicha prolongación de la privación de libertad solo se produzca con respeto de los derechos fundamentales (incluida la prohibición de una duración excesiva, el respeto de la proporcionalidad y la presunción de inocencia) y para que, en caso de levantarse, se adopten las medidas necesarias para evitar la fuga o que se frustre la entrega ${ }^{77}$.

Esto podría llevar a entender que el Tribunal ha rechazado la existencia de la excepción y solo ha admitido una suspensión o un aplazamiento. Pero, es difícil concordar con esta idea si se atiende al apartado último y fallo de la sentencia, según el cual, si la autoridad de ejecución no puede excluir la

73 Sentencia Aranyosi y Căldăraru, apdo. 95.

74 Sentencia Aranyosi y Căldăraru, apdo. 96. La solicitud de esta información puede ser relevante si se conecta con lo señalado en el apdo. 103, según el cual la entrega se puede producir «sin perjuicio de que la persona de que se trate pueda, una vez entregada, hacer uso de los medios de recurso previstos en el ordenamiento jurídico del Estado miembro emisor que le permitan impugnar, en su caso, la legalidad de sus condiciones de reclusión en un establecimiento penitenciario de ese Estado miembro». Al mencionar la existencia de estos mecanismos y recursos, el Tribunal, aunque sibilinamente, le da al juez de ejecución argumentos para no ser estricto en la apreciación del riesgo real.

75 Sentencia Aranyosi y Căldăraru, apdo. 97. Un intercambio de información, cuya celeridad el Tribunal trata de incentivar recordando el límite temporal establecido para la adopción de la decisión definitiva.

76 Sentencia Aranyosi y Căldăraru, apdo. 98. En el asunto Lanigan la cuestión era si, por el mero transcurso del período máximo de duración establecido en la Decisión Marco, el juez de ejecución debía poner fin al procedimiento y, en consecuencia, a la detención del individuo.

77 Sentencia Aranyosi y Căldăraru, apdos. 101-103. 
existencia del riesgo concreto en un plazo razonable, deberá decidir si procede poner fin al procedimiento de entrega ${ }^{78}$.

Creo que el sentido de este aplazamiento de la decisión es la de continuar sujetando procedimentalmente esta situación e involucrar a Eurojust y al Consejo en su gestión, lo que puede confesarse como uno de los grandes aciertos de este pronunciamiento. Para ello, el Tribunal ha debido realizar un pequeño juego malabar, instrumentando el art. 17 de la Decisión Marco, pensado para las demoras, a estos fines. Lo cierto es que si la decisión se aplaza pero no se abandona el procedimiento, por definición se excederá del tiempo máximo establecido y habrá en consecuencia demora, por lo que el Estado miembro — y no la autoridad judicial ${ }^{79}$ — deberá informar a Eurojust de esta demora y de la razón que la motiva. La reiteración de estas «demoras» permitirá remitir la cuestión al Consejo a efectos de evaluar la aplicación de la Decisión Marco. El acierto, a mi modo de ver, está en que Eurojust por su composición y competencias es, quizá, el foro más adecuado para gestionar un problema aislado de este tipo que surja entre autoridades judiciales de dos Estados miembros ${ }^{80}$, mientras que la reiteración de estos casos apuntará a un problema político de fondo y la remisión al Consejo parece más que conveniente.

Esta excepción acogida por el Tribunal presenta, no obstante, unos perfiles inciertos referidos a su alcance que la doctrina ha inmediatamente advertido,

78 Sentencia Aranyosi y Căldăraru, apdo. 104. En este sentido Szilárd GÁSPÁR-SZILÁGY, op. cit. nota 46, pp. 216-217, que además critica la confusión que puede producir para el juez nacional el "plazo razonable» en el que decidir la existencia del riesgo y la duración excesiva de la detención. Otros han apuntado que la razón de este lenguaje florentino es evitar que una excepción abierta pudiera cuestionar el principio de reconocimiento mutuo en la línea de las conclusiones; lo que, atendido el escaso uso de la excepción por los Estados que la han transpuesto en su legislación, les parece poco justificado (Emmanuelle BRIBOSIA y Anne WEYEMBERGH, op. cit. nota 46, p. 227).

79 La demora en el cumplimiento del plazo fijado y los motivos que la causan debe ser comunicada por la autoridad judicial de ejecución a la de emisión, pero estas no están obligadas (aunque nada lo impediría) a comunicarlo a Eurojust.

80 Véanse, en particular, los arts. 7, 9 ter y 9 sexies de la Decisión 2002/187/JAI, actualizada en 2009, que establecen las competencias del Colegio para recomendar una solución y de las competencias que, como mínimo, podrán desempeñar los miembros nacionales. Adicionalmente, las dificultades o el incumplimiento de la autoridad de emisión respecto de la información complementaria o la correcta actualización de la situación de deficiencia sistémica en el Estado de emisión, puede encontrar en Eurojust, el mejor foro de asistencia e información para la autoridad de ejecución que se ha encontrado con esta situación. 
tratando de identificar, a veces con argumentos a contrario, los casos en los que no operaría. Existe una certeza y es lo que cubre la excepción admitida: cuando por la existencia de deficiencias sistémicas en un Estado (condiciones de detención o prisión), no sea posible descartar que un sujeto concreto sufra un riesgo real de sufrir una violación de un derecho fundamental inderogable (un trato inhumano o degradante), no procede el reconocimiento (la entrega). Pero, a partir de esta certeza solo relativa ${ }^{81}$, las incertidumbres se multiplican en: a) la extensión de la excepción aceptada a otros instrumentos o supuestos; b) los derechos fundamentales cubiertos; c) la dimensión temporal de las violaciones frente a la que opera, y d) sus efectos sobre el derecho derivado y las respectivas transposiciones nacionales. Veámoslo:

a) hay una obvia extensión a todos los demás instrumentos en los que el supuesto de hecho sea transferible, como la Decisión Marco 2008/909/JAI para cumplimiento de una sentencia privativa de libertad que menciona el abogado general ${ }^{82}$. Pero, como siempre que hablamos de reconocimiento mutuo, conviene ver las cosas en ambas direcciones y la excepción es, en teoría, muy extrapolable (incluido, para el juez de emisión) en sentidos bastante más inciertos que se ven mejor si le damos nombre: ¿debería un juez alemán inhibirse de emitir la orden europea contra un individuo residente en Hungría, o retirarla una vez conocida la detención, debido a las condiciones de detención en dicho país?; ¿qué ocurre cuando en ejecución de una euroorden el juez de ejecución en Budapest entrega al sujeto (húngaro) bajo la condición de que, una vez juzgado, cumpla la pena en dicho país?; ¿opera la excepción en caso de consentimiento de un ciudadano (rumano o no) a la entrega a las autoridades rumanas para ser juzgado o para cumplir una sentencia? Estas preguntas plantean incógnitas difíciles de resolver porque muestran que una excepción, aún tan ceñida como la aceptada por el Tribunal, multiplica sus prolongaciones y trae al debate cuestiones muy complejas (adicionales a la generación de impunidad o de disfunciones en los sistemas penitenciarios de los Estados miembros), como la relación entre un derecho

81 Incluso, sin salir del art. $3 \mathrm{CEDH}$, quedaría el problema (extremadamente relevante para España dadas las condenas recurrentes) de la violación del procedural limb de este derecho que obliga a los Estados a investigar diligentemente las alegaciones de vulneración del art. 3 CEDH (véase Santiago RIPOL CARULLA, «Un nuevo marco de relación entre el Tribunal Constitucional y el Tribunal Europeo de Derechos Humanos», Revista Española de Derecho Internacional, vol. 66, 2014, pp. 32-36).

82 Conclusiones Bot Aranyosi y Căldăraru, punto 128. 
inderogable y el consentimiento del sujeto, eventualmente para apreciar dónde debe producirse su reinserción social ${ }^{83}$. Únase a ello que el doble test que permite que la autoridad de ejecución obtenga garantías de que el sujeto en concreto no sufrirá un riesgo real de trato degradante, dentro de una situación de deficiencias sistémicas (por ejemplo, especificando un centro penitenciario no afectado por ellas o asegurando que no será mantenido en prisión provisional mientras se desarrolla el juicio) suscita naturalmente la cuestión del respeto al principio de igualdad en el Estado de ejecución ${ }^{84}$.

b) Los perfiles son aún más inciertos cuando se trata de determinar la violación de qué derechos fundamentales desencadena la excepción. El razonamiento del Tribunal con su énfasis en el carácter inderogable de la prohibición de la tortura y el trato inhumano o degradante parece reducir la posibilidad de invocar esta excepción a los casos de derechos inderogables (como sería el caso del principio de legalidad penal), pero más allá (y la llamada a la dignidad no parece ayudar en exceso ${ }^{85}$ ) los perfiles se difuminan incluyendo naturalmente la complejidad de determinar el alcance preciso con el que el derecho al proceso equitativo lo es. La clave está aquí en que, por derogable o restringible que sea un derecho fundamental, esto no lo priva de la posibilidad de ser violado de manera sistemática y las distintas sentencias piloto referentes, por ejemplo, a la

83 Las posibilidades de que esto ocurra y deba resolverse son, como hemos visto, reales, pues no cabe entender que dicha cuestión esté enteramente resuelta por la consideración, discutida por algunos autores, de que la excepción opere exclusivamente a instancia de parte y no deba ser apreciada de oficio por la autoridad judicial concernida, o por la inclusión en algunos instrumentos, de la necesidad de contar con el consentimiento del sujeto para ciertos casos de reconocimiento.

Véase Gabriele ASTA, op. cit. nota 46, p. 13, o la posición de Rumanía en la vista cifrada en Henning BANG FUGLSANG MADSEN SØRENSEN, loc. cit. nota 36.

El Tribunal de Justicia parece abrir, frente a su jurisprudencia Omega (Sentencia de 14 de octubre de 2004 Omega, C-36/02, EU:C:2004:614, apdos. 30-38) un nuevo camino para una elaboración de la dignidad como categoría propia (autónoma) del derecho de la Unión en materia de derechos fundamentales. La lectura en clave de respuesta al Tribunal Constitucional Federal alemán parece inevitable (Julian NOWAG, «EU law, constitutional identity, and human dignity: A toxic mix? Bundesverfassungsgericht: Mr R», Common Market Law Review, vol. 53, núm. 5, 2016, pp. 1441-1454) y las comparaciones con lo ocurrido en el caso Melloni algo dolorosas para nuestro Tribunal Constitucional, donde su argumentación sobre la dignidad humana en el mismo contexto de juicios en ausencia fue simple y llanamente inatendida por el Tribunal de Justicia. 
violación del art. $6 \mathrm{CEDH}$ como consecuencia de una excesiva duración de los procedimientos, lo prueban ${ }^{86}$. Teniendo en cuenta el Brexit, podría parecer impropio plantearlo, pero la condena a Gran Bretaña por la privación del derecho de voto a la población reclusa, en una sentencia piloto $^{87}$, suministra el ejemplo prototípico: siendo un derecho derogable o, como mínimo restringible, ¿se quedaría fuera de esta excepción la ejecución de órdenes de detención europeas con destino a prisiones británicas, incluso si atendemos al estatuto de ciudadanía? ${ }^{88}$

c) En tercer lugar, como también se ha señalado, queda irresuelta la cuestión de si la excepción solo puede amparar violaciones futuras o también debería cubrir violaciones pasadas, cuestión que el Tribunal sorteó en el asunto Radu y que, por el contrario, la abogado general Sharpston respondió de manera afirmativa ${ }^{89}$. Dos elementos rodean esta cuestión de la mayor ambigüedad: una primera, muy clara, es si la violación pasada quedaría sujeta a la exigencia de deficiencias

86 Una reseña actualizada de estas sentencias piloto puede consultarse en el Factsheet sobre «Pilot Judgments», elaborado por la Unidad de prensa del TEDH, Strasbourg, September 2016, pp. 2-6.

87 Greens and M.T. v. the United Kingdom, 60041/08 and 60054/08, 23.11.2010, constatando cinco años después que no había habido modificación normativa alguna tras la Sentencia Hirst (num. 2) v. the United Kingdom, 74025/01, 6 October 2005. Tras el período para adaptarse a la sentencia piloto, el TEDH retomó el enjuiciamiento que ha llevado a nuevas condenas del Reino Unido: Firth and Others $v$. the United Kingdom, 47784/09, 47806/09, 47812/09, 47818/09, 47829/09, 49001/09, 49007/09, 49018/09, 49033/09 and 49036/09, 12 August $2014 \mathrm{y}$, especialmente, Millbank and Others $v$. the United Kingdom, 44473/14, 58659/14, 70874/14, 71699/14, 73574/14, 73638/14, 73771/14, 73783/14, 73909/14, 73911/14, 74403/14, 74409/14, $75735 / 14,75846 / 14,2294 / 15,18149 / 15,24868 / 15,26031 / 15,26045 / 15$, 28688/15, 32681/15 and 32685/15, 30 June 2016, donde 14 de los demandantes alegaban la privación respecto de las elecciones al Parlamento Europeo de 2014. Es discutible que la sentencia de 6 de octubre de 2015, Delvigne, C-650/13, EU:C:2015:648, donde el TJUE considera justificada, y compatible con el estatuto de ciudadanía, la privación del derecho de sufragio sea trasladable al supuesto anterior, pues se sostiene sobre argumentos de temporalidad (sentencia firme anterior a una reforma que eliminó la automaticidad de esta privación en derecho francés), proporcionalidad y posibilidad de solicitar la reconsideración de tal pena accesoria.

89 Conclusiones de la abogado general Sharpston en el asunto Radu, C-396/1, EU:C:2012:648, puntos 72-97, donde señala que el umbral de la denegación flagrante del derecho al proceso debido del TEDH es demasiado difuso y propone que este se concentre en la prueba de «vulneraciones que destruyan sustancialmente la equidad del proceso», operando para aquellas pasadas la exclusión de las que son subsanables. 
sistémicas, toda vez que la violación in concreto ha sido probada y, segunda, si en este caso la regla del agotamiento de los recursos internos operaría como limitador de ella. Fuera del derecho fundamental e instrumento de cooperación judicial acogidos expresamente en esta excepción, las posibilidades son claramente imaginables, pero desde el momento en que la euroorden conlleva la entrega (¿male captus, bene detentus?) o posibilita articular la toma de declaración del individuo de conformidad con el art. 19 de la Decisión Marco, el supuesto, por artificioso que parezca, es posible.

d) Finalmente, cabe plantearse los efectos de esta jurisprudencia sobre el derecho derivado y su aplicación en los Estados miembros. Al establecer en qué medida un Estado miembro puede rechazar el reconocimiento como consecuencia de la violación de derechos fundamentales en otro, parece muy probable que, vía principio de interpretación conforme, repercuta sobre todas aquellas transposiciones de la Decisión Marco 2002/584/JAI que han introducido dicha excepción, eludiendo una más problemática primacía $a^{90}$. Por el contrario, que esta jurisprudencia pueda condicionar una interpretación estricta de los instrumentos de cooperación judicial penal que contemplan una excepción de respeto de derechos fundamentales dentro de los motivos de denegación facultativa del reconocimiento parece más improbable, aunque no fuera enteramente descartable. Sin embargo, ambos efectos, por lo que se dirá seguidamente, no me parecen del todo apropiados, porque (y esto vale tanto para la solución que propone el abogado general como la del Tribunal de Justicia), están mezclando la forma en que el respeto de los derechos fundamentales se presenta en dos cuestiones distintas: en los límites al reconocimiento mutuo y en los límites de la confianza mutua.

\section{LA JUSTIFICACIÓN DE LOS LÍMITES «CONSTITUCIONALES» DE LA CONFIANZA MUTUA}

A pesar de sus inciertos perfiles técnico-jurídicos, la admisión de esta excepción será valorada positivamente como muestra de una reciente tendencia de Luxemburgo que, al igual que Bruselas desde el Programa de

90 Esto que ocurre, de hecho, con la transposición alemana y parece haberse materializado ya en otros Estados miembros: véase la Sentencia de 3 de junio de 2016 de la Corte di cassazione italiana en el caso Barbu analizada por Gabriele ASTA, op. cit. nota 46, pp. 13-15. 
Estocolmo, está más atenta a los derechos fundamentales dentro del ELSJ. Desde el momento en que el foco se ponga en la protección de los derechos fundamentales, su valoración desde la perspectiva de la convivencia con los sistemas de protección constitucionales y del CEDH será un paso obligado. No faltarán quienes alerten de las dificultades que creará en el funcionamiento del principio de reconocimiento mutuo dentro de ese espacio. En unos y otros, acaso, subyazca la percepción de que la sentencia, a fin de cuentas, no resulta tan innovadora y extiende lo ya habido en asilo a la cooperación judicial penal. Posiblemente, todos esos enfoques son correctos y suscitarán debates pertinentes.

En esa idea de contribuir al debate, creo que los asuntos Aranyosi y Căldăraru permiten reflexionar sobre dos aspectos distintos aunque interrelacionados: primero, la necesidad de distinguir más claramente entre reconocimiento mutuo y confianza mutua a fin de observar que las normas de derecho derivado no pueden resolver una cuestión que necesariamente pertenece al derecho originario y, segundo, que solo la modificación de este derecho podría alterar la afirmación de que la confianza mutua está limitada, en la forma que sea, por el respeto de los derechos fundamentales. En ambos aspectos, la cuestión de la convivencia con los sistemas de protección constitucionales y del CEDH se presenta, pero, a diferencia de lo que yo mismo he sostenido, comienzo a pensar que las repercusiones sobre esa convivencia son una cuestión ajena o, todo lo más, suscitan aspectos que es conveniente tener en cuenta al analizar los perfiles técnico-jurídicos de la limitación, pero, desde luego, no en su afirmación y ello a pesar del ruidoso impacto que causan las fricciones entre los conspicuos tribunales que están al frente de esos sistemas ${ }^{91}$. Tales fricciones están en la sintomatología pero no en la etiología. Trataré de desarrollar estas ideas.

91 Dado el efecto extraterritorial que el reconocimiento mutuo supone, ha sido lógica la asociación de sus límites con la importación de la jurisprudencia del TEDH en materia de vulneraciones indirectas o víctimas par ricochet. Justamente, entiende que esas son las "circunstancias excepcionales» en las que la confianza mutua no opera Nicole LAZZERINI, «Gli obblighi in materia di protezione dei diritti fondamentali come limite all'esecuzione del mandato di arresto: la sentenza Aranyosi e Căldăraru», Diritti umani e diritto internazionale, vol. 10, 2016, pp. 445-453. La conexión con los sistemas constitucionales y el CEDH es, igualmente, atendida como la clave por Leonard F.M. BESSELINK y Jan-Herman REESTMANEL, "Editorial. Sandwiched Between Strasbourg and Karlsruhe: EU Fundamental Rights Protection», European Constitutional Law Review, vol. 12, 2016, pp. 213-222). 


\section{DIFERENCIANDO RECONOCIMIENTO MUTUO Y CONFIANZA MUTUA}

Resulta necesario comenzar distinguiendo con claridad entre reconocimiento mutuo y confianza mutua y la primera diferencia es la forma en que están incluidos en el derecho originario. El reconocimiento mutuo se encuentra explícitamente recogido en los Tratados como una técnica (si se quiere «la» técnica —art. 82 TFUE—) de cooperación judicial penal para la consecución de un nivel adecuado de seguridad en la prevención y lucha contra la delincuencia dentro de un espacio sin fronteras interiores que respeta los derechos fundamentales y los sistemas y tradiciones jurídicos de los Estados miembros (art. 67 TFUE). Por el contrario, la confianza mutua no está explicitada en los Tratados. Esto no significa, en mi opinión, que su inclusión como parte del derecho de la Unión, es decir, su carácter de principio fundamental del orden jurídico europeo no sea claro ${ }^{92}$, ni que se trate de un concepto subjetivo ${ }^{93} \mathrm{o} \mathrm{de}$ imposible escrutinio judicial ${ }^{94}$, sino que su contenido es referencial, esto es, no autónomo. El razonamiento sería distinto si la confianza mutua estuviera contemplada en el art. 2 TUE como uno de los valores en que se basa la Unión o hubiese una cláusula en los Tratados que prescribiese que los Estados miembros se deberán confianza mutua (una auténtica full faith and credit clause) ${ }^{95}$.

92 Véase Koen LEANERTS, «The Principle of Mutual Recognition in the Area of Freedom, Security and Justice», The Fourth Annual Sir Jeremy Lever Lecture All Souls College, University of Oxford, 30 January 2015. También supra nota 10.

93 Valsamis MITSILEGAS, "The Symbiotic Relationship Between Mutual Trust and Fundamental Rights in Europe's Area of Criminal Justice», New Journal of European Criminal Law, vol. 6, 2015, pp. 457-480, y más claramente en «Mutual recognition, mutual trust and fundamental rights after Lisbon», en V. MITSILEGAS et al. (eds.), Research Handbook on EU Criminal Law, Elgar, Cheltenham, 2016, p. 160.

Ester HERLIN-KARNELL, "Constitutional Principles in the EU Area of Freedom, Security and Justice», en D. ACOSTA y C. MURPHY (eds.), EU Security and Justice Law, Hart Publishing, Oxford, 2014, p. 36.

95 La sección I del art. IV de la Constitución americana prescribe: «Full Faith and Credit shall be given in each State to the public Acts, Records, and judicial Proceedings of every other State. And the Congress may by general Laws prescribe the Manner in which such Acts, Records and Proceedings shall be proved, and the Effect thereof». Ello se completa con el párrafo $2^{\circ}$ de la sección 2 de este art. relativo a la extradición entre los Estados: «A Person charged in any State with Treason, Felony, or other Crime, who shall flee from Justice, and be found in another State, shall on Demand of the executive Authority of the State from which he fled, be delivered up, to be removed to the State having Jurisdiction of the Crime». Véase al respecto, aunque referido al ámbito solo en apariencia menos turbulento de la cooperación judicial civil, la interesante contribución de Agnieszka FRACKOWIAK-ADAMSKA, «Time 
En tal caso, el principio de confianza mutua podría desarrollar un contenido propio o autónomo, pero hasta tanto, este principio no puede ser más de lo que ha dicho el Tribunal: el resultado de que los Estados miembros y la Unión se basan en valores comunes, incluidos el estado de derecho y el respeto de los derechos fundamentales. Son tales valores comunes los que resultan en una equivalencia entre los sistemas jurídicos de los Estados miembros (incluidos sus sistemas judiciales, también pero no solo penales) y, en consecuencia, los que permiten presumir, si es que no obligan a ello, que los Estados cumplen con el derecho (incluido el de la Unión) y respetan los derechos fundamentales (incluso fuera del ámbito competencial del derecho de la Unión) ${ }^{96}$.

Así planteado, aún sin armonización sustantiva o procesal penal, la confianza mutua permite, en efecto, el reconocimiento de resoluciones penales de los otros Estados. Esto significa que donde no hay confianza mutua no puede haber reconocimiento mutuo, pero no que donde no hay reconocimiento mutuo no haya confianza mutua. Esta confusión entre confianza mutua y motivos de denegación del reconocimiento, sobre la que ya advirtió Peers tempranamente con motivo de la supresión de la exigencia de doble tipificación ${ }^{97}$, es muy perniciosa porque la denegación del reconocimiento no se basa, necesariamente, en la ausencia de confianza mutua y un repaso somero por los motivos previstos claramente lo prueba ${ }^{98}$. Más aún, de existir esa relación automática entre confianza mutua y denegación del reconocimiento, la previsión en el derecho derivado de un motivo de denegación basado en el respeto de derechos humanos, como ocurre con la reciente orden europea de investigación, sería, una de dos, inválido por violación del principio de

for a European "Full Faith and Credit Clause"», CMLR, vol. 52, 2015, pp. 191-218, donde argumenta que esta puede postularse bien mediante Derecho secundario, bien mediante una interpretación, que admite difícil, de los arts. respectivos del TFUE reconociéndoles eficacia directa.

96 Sentencia del Tribunal de Justicia de 30 de mayo de 2013 Jeremy F., C-168/13 PPU, EU:C:2013:358, apdo. 48.

97 Steve PEERS, «Mutual Recognition...», op. cit. nota 7, p. 26.

98 Obviamente, la previsión la minoría de edad penal como motivo obligatorio de denegación del reconocimiento no se justifica porque los Estados crean que los demás Estados no respetan el derecho o los derechos fundamentales en el enjuiciamiento de menores. Más absurdo aún sería trasladar este razonamiento a la posibilidad de exigir la doble tipificación para las conductas excluidas del listado o incluso contempladas en dicho listado si no alcanzan el mínimo máximo penológico. Llevado al extremo, conllevaría la absurda conclusión de la existencia de confianza mutua para cumplir una pena de privación de libertad, pero no para ejecutar una diligencia probatoria, ambas establecidas en una resolución judicial de otro Estado miembro. 
derecho originario de la confianza mutua o la manifestación de que el reconocimiento puede operar en ausencia de confianza mutua y, en consecuencia, no se deriva de ella la conclusión que el TJUE le asocia en el Dictamen 2/13: la imposibilidad de verificar, en un caso concreto, que otro Estado miembro ha respetado los derechos fundamentales. De hecho, tengo la impresión de que, tras la común asunción de que se debería establecer esta excepción con carácter general en todos los instrumentos de reconocimiento mutuo ${ }^{99}$, se encuentran ambas premisas: 1) que su aceptación no es un obstáculo real al funcionamiento del ELSJ, como su escaso uso hasta ahora prueba ${ }^{100}$, y 2) la negación de que la confianza mutua puede actuar como premisa normativa y la consecuente afirmación de que esta es realmente el fruto, bien intencional de una armonización previa, bien espontáneo de la práctica del reconocimiento con control externo del respeto de derechos fundamentales por los demás Estados miembros ${ }^{101}$. Cuestión muy distinta es si este debate no es solo doctrinal, sino también interinstitucional ${ }^{102}$.

99 Véase, ad ex., Martin BÖSE, «Human Rights Violations and Mutual Trust: Recent Case Law on the European Arrest Warrant», en S. RUGGERI (ed.), Human Rights in European Criminal Law, Springer, 2015, pp.144-145; Lorena BACHMAIER WINTER, «Quo Vadis - El TJUE y su papel en materia de cooperación penal al hilo de la reciente jurisprudencia sobre la orden de detención y entrega», $R G D E$, núm. 38, 2016, pp. 31-ss.; Roberto SERRANO AMADO y David VALLESPÍN PÉREZ, «La euroorden y el respeto de los derechos fundamentales», en F. DONAIRE VILLA (ed.), Técnicas y ámbitos de coordinación en el Espacio de Libertad, Seguridad y Justicia, Marcial Pons, Madrid, 2015, pp. 103-106.

100 Anne WEYEMBERGH, Inés ARMADA y Chloé BRIÈRE, op. cit. nota 15, pp. I-8-I-13.

101 Esta posición, como se puede observar, es de muy profundo alcance, porque sus fundamentos normativos (el art. 6 TUE y la Carta en última instancia) se proyectan por igual sobre todas las políticas de la Unión y, en buena lid, deberían reflejarse sobre cualquier otro contenido del derecho de la Unión. Creo que la asunción de esa excepción no podría, siquiera, limitarse al ELSJ.

102 Cabe preguntarse si los avances legislativos en este espacio, en realidad, están trasladando un debate más de fondo, esto es, si la posición del «legislador europeo» está rechazando que la confianza mutua pueda definirse en términos de premisa normativa (como la asumida por el Tribunal) y deba confinarse a una concepción más basada en la equivalencia material o en el resultado espontáneo de un reconocimiento mutuo con control externo. El tenor del considerando 5 de la Directiva 2013/48/UE, de 22 de octubre de 2013, sobre el derecho a la asistencia de letrado en los procesos penales y en los procedimientos relativos a la orden de detención europea, y sobre el derecho a que se informe a un tercero en el momento de la privación de libertad y a comunicarse con terceros y con autoridades consulares durante la privación de libertad (DO L 294, 
Por esta razón, el análisis de las excepciones al reconocimiento mutuo recogidas en las normas de derecho secundario no resuelve la cuestión de los límites de la confianza mutua que deben ser deducidos del derecho primario, aunque tales motivos de denegación puedan, eventualmente y de forma muy natural, canalizar dichos límites. Se impone, pues, determinar cuáles son esos límites.

\section{LOS LÍMITES DE DERECHO ORIGINARIO DE LA CONFIANZA MUTUA Y LA JUSTA MEDIDA EN QUE LA CUESTIÓN COMPETENCIAL ES RELEVANTE}

Referida la confianza mutua a los valores comunes de la Unión y sus Estados miembros, esta solo puede perdurar mientras perduran esos valores comunes a la Unión y a sus Estados miembros. Esto es, la confianza mutua desaparece en el momento en que un Estado miembro deja de compartirlos (pues no habría podido adherirse de no haberlo hecho nunca). En este sentido, los límites de la confianza mutua solo pueden aparecer de forma reactiva, cuando un Estado se aparta de ellos, y es, por esta razón, correcta la conexión que tanto abogado general como Tribunal hacen entre confianza mutua y art. 7 TUE. Este art., como es sabido, prevé un procedimiento de control y sanción para aquellos Estados que violan grave y persistentemente los valores recogidos en el art. 2 TUE, cuyo carácter disfuncional es patente si se observa su práctica hasta ahora y la necesidad continua de crear procedimientos previos, menos estrictos, que adelantan su activación a situaciones teóricamente menos graves de vulneración de tales valores ${ }^{103}$.

Sin embargo, mientras que resulta correcto el considerando 10 de la Decisión Marco cuando señala que solo podrá suspenderse el sistema en sí de la

de 6 de noviembre de 2013, p. 1) o de la más reciente Directiva (UE) 2016/343 del Parlamento Europeo y del Consejo, de 9 de marzo de 2016, por la que se refuerzan en el proceso penal determinados aspectos de la presunción de inocencia y el derecho a estar presente en el juicio (DO L 65, de 11 de marzo de 2016, p. 1) es ilustrativo: «Aunque los Estados miembros son partes en el CEDH y en el Pacto, la experiencia ha puesto de manifiesto que, por sí sola, esa circunstancia no siempre aporta el grado de confianza suficiente en los sistemas judiciales penales de los demás Estados miembros».

103 Araceli MANGAS MARTÍN y Diego J. LIÑÁN NOGUERAS, op. cit. nota 14, pp. 143-146. Véase sobre su puesta en práctica en el caso polaco Carmela PÉREZ BERNÁRDEZ, «La Unión Europea frente a la erosión del Estado de Derecho: las respuestas jurídico-políticas al caso polaco", Revista General de Derecho Europeo, núm. 40, 2016, pp. 48-95). 
euroentrega en virtud de este procedimiento, no lo es que la desaparición de la confianza mutua solo pueda determinarse por tal vía, como parece inferir el abogado general. Sostener esta posición significaría que la confianza mutua, en efecto, es subjetiva, pues depende de los Estados representados en el Consejo, donde reside la determinación de tal violación y que, además, no es susceptible de control judicial, pues las competencias del TJUE se encuentran limitadas a la verificación del respeto de las reglas procedimentales, pero no de la decisión sustantiva (art. 269 TFUE). Esto es, al Tribunal le estaría vedado determinar si, en efecto, un Estado miembro está violando de manera grave y persistente los valores en los que se cimentan la Unión y sus Estados miembros y, por lo que interesa a la confianza mutua, el respeto de los derechos fundamentales ${ }^{104}$. Esta interpretación, creo, no es sostenible fundamentalmente porque es contraria al propio art. 2 del TUE, entre cuyos valores está, precisamente, el Estado de Derecho.

Naturalmente, las competencias del TJUE se extienden más allá de la concedida en el art. 269 TFUE, por lo que la garantía jurisdiccional del respeto de los derechos fundamentales por parte de los Estados miembros o, si se quiere, la determinación de que los Estados miembros se deben confianza mutua porque conceden una protección equivalente o, al contrario esta ha decaído, queda articulada por el sistema general. Justamente es aquí donde la problemática de la competencia de la Unión (y del propio TJUE) en materia de derechos fundamentales cobra relevancia, pues, como es sabido, esta solo opera en la medida en que una situación entre dentro del ámbito del derecho de la Unión Europea y los asuntos Aranyosi y Căldăraru nos suministran un ejemplo donde ilustrarlo respecto de las condiciones de detención y reclusión en los Estados miembros.

No se trata de que la Unión carezca de competencia para regular las condiciones de detención y reclusión. Estoy de acuerdo con el abogado general cuando señala que el art. 82 TFUE otorga base jurídica suficiente: la armonización de tales condiciones puede ser necesaria para facilitar el reconocimiento mutuo ${ }^{105}$. Sin embargo, mientras la Unión no ejerza dicha competencia compartida (art. 4 TFUE), la regulación de tales condiciones corresponde a los Estados miembros. De esta manera, un Estado cuyas condiciones de detención y reclusión vulneran la prohibición del trato inhumano o degradante

104 Sobre este procedimiento, sus deficiencias e incertidumbres y las iniciativas que han desembocado en un mecanismo de control pre-art. 7 TUE, Véase Editorial Comment, "Safeguarding EU values in the Member States - Is something finally happening?, Common Market Law Review, vol. 52, 2015, pp. 619-628.

105 Conclusiones Bot Aranyosi y Căldăraru, punto 182. 
no está violando per se el derecho de la Unión. La violación del derecho de la Unión, esto es, del art. 4 de la Carta, solo se produce (y el Tribunal podrá entrar a garantizar su respeto) cuando el trato inhumano o degradante se inflige en un caso en que el Estado está aplicando el derecho de la Unión en el sentido del art. 51.1 de la Carta, como por ejemplo, cuando emite o ejecuta un instrumento de cooperación judicial penal ${ }^{106}$. Esta particular articulación de la protección de los derechos fundamentales en la Unión desemboca en tres consideraciones que, a mi juicio, en lugar de conducir a la negación de carácter enjuiciable de la confianza mutua, resultan en la necesidad de aceptar la excepción en los términos en los que el Tribunal la ha concebido.

En primer lugar, debe reconocerse que el ámbito de aplicación del derecho de la Unión, por ampliamente que haya sido interpretado por el TJUE a efectos de garantizar el respeto de derechos fundamentales, es por definición inferior al referente de protección al que la confianza mutua está vinculada, pues esta precisa e incluye que los Estados miembros respeten los derechos fundamentales aún fuera del ámbito de la Unión, como reconoció el Tribunal en la sentencia Jeremy F. En este sentido, la apreciación de la desaparición de la equivalencia que fundamenta la confianza mutua excede del ámbito de protección jurisdiccional de los derechos fundamentales que el Tribunal puede desplegar porque necesariamente incluye aquellos ámbitos que se encuentran fuera del derecho de la Unión ${ }^{107}$, en este caso, las condiciones de detención per se en los Estados miembros.

En segundo lugar, a pesar de que la cuestión competencial es como vemos determinante, creo que hay que deshacerse de la visión de que la confianza mutua no tendría límites en la protección de derechos fundamentales en caso de desarrollarse enteramente dentro del ámbito de aplicación del derecho de la Unión. Esto es, que una vez conseguida la armonización, la cuestión de la desaparición de la confianza mutua y sus efectos ya no se plantearía ${ }^{108}$. Obviamente, disponer de lo que se ha denominado level playing field facilita y refuerza la confianza mutua ${ }^{109}$ y posibilita, desde luego, que el Tribunal juzgue

106 Véase en este sentido y con relación al asunto Gueye, Koen LENAERTS y José A. GUTIÉRREZ-FONS, «The European Court of Justice and fundamental rights in the field of criminal law», en V. MITSILEGAS et al. (eds.), Research Handbook on EU Criminal Law, Elgar, Cheltenham, 2016, p. 14.

107 En este sentido, Nicole LAZZERINI, op. cit. nota 91, pp. 445-453.

108 En sentido parecido, Anne WEYWMBERGH, Inés ARMADA y Chloé BRIÈRE, op. cit. nota 15 , p. I-11.

109 Koen LENAERTS, op. cit. nota 92, p. 9. En particular, porque su presencia extiende de manera natural el alcance de la Carta, dada la interpretación que el Tribunal de Justicia ha dado a la obligación de respeto de los derechos fundamentales cuando los 
si un Estado lo está violando grave y persistentemente por vía de un recurso de incumplimiento (imposible si no existe tal armonización). Pero, como el asunto $N$. S. atestigua, disponer de dicho level playing field no garantiza que la violación sistémica no se produzca sin que medie una sentencia declarativa de tamaño incumplimiento ${ }^{110}$.

En tercer y último lugar, la confianza recíproca entre Estados miembros atiende como hemos visto a la equivalencia en la protección de derechos fundamentales que generan los valores compartidos del art. 2 TUE. La equivalencia de tales sistemas no se pone en entredicho por la producción de una violación singular de cualquier derecho fundamental. En todos los sistemas jurídicos de los Estados miembros se producen tales violaciones singulares de esos derechos y, a tal efecto, disponen de un sistema de recursos jurisdiccionales para su garantía. De hecho, en todos ellos y a pesar de haber agotado los recursos internos, los mecanismos de control internacional del respeto de estos derechos estiman que se ha producido una violación: las sentencias del TEDH nos recuerdan esto constantemente. En este sentido, la equivalencia no es cuestionada por una violación singular de un derecho fundamental; antes bien, resulta afirmada.

En tales casos, la confianza mutua no queda, a mi juicio, comprometida, lo que no significa que el derecho de la Unión carezca de mecanismos de reacción: posee un sistema de recursos judiciales, incluida la cuestión prejudicial; está dotado de un sistema por el que el Estado deberá responder de la violación suficientemente caracterizada del derecho de la Unión (y compris los derechos fundamentales que este protege) e, incluso, dispone de herramientas que posibilitarían la revisión de sentencias firmes contrarias al derecho de la Unión. Lo que no tiene, como sabemos, es un sistema de control externo. Pero, es más, si hemos de ser estrictos, en la medida en que los Estados miembros sí lo tienen y este puede penetrar cuando actúan en aplicación del derecho de la Unión, la Unión dispone parcialmente de este control externo, si bien no se traduce en su responsabilidad internacional por incumplimiento.

Estados apliquen el derecho de la Unión contenida en el art. 51 (véase al respecto, Daniel SARMIENTO, «Who's afraid of the Charter? The Court of Justice, national courts and the new framework of fundamental rights protection in Europe», Common Market Law Review, vol. 50, 2013, pp. 1267-1304).

${ }^{110}$ De hecho, salvo error mío, no existe ninguna sentencia del Tribunal de Justicia que haya condenado a Grecia como consecuencia de la violación sistemática y persistente de la Directiva de procedimiento respetando los derechos fundamentales reconocidos y protegidos por el derecho de la Unión dictada con posterioridad a la sentencia $N$. $S$. que, recuérdese, es de 2011. 
Sin embargo, frente a este arsenal jurídico para reaccionar a violaciones concretas (siempre que se produzcan dentro del ámbito del derecho de la Unión), los instrumentos jurisdiccionales para atajar violaciones graves y persistentes de los derechos fundamentales son, como hemos visto, mucho más reducidos y, para las que escapan a su ámbito de aplicación, inexistentes. Por eso, creo que, dada esta configuración del principio de confianza mutua en el derecho originario, no cabe otra alternativa que el reconocimiento de la excepción a cargo de los demás Estados miembros (ese llamado horizontal Solange ${ }^{111}$ ) y el reconocimiento de las fuentes (especialmente jurisdiccionales) externas al derecho de la Unión para su apreciación. Esto es, finalmente, lo que, en mi opinión, hace la sentencia dictada por el Tribunal de Justicia el pasado 5 de abril en los asuntos Aranyosi y Căldăraru: alumbrar los límites constitucionales de la confianza mutua e importar las vías por las que se pueden constatar. Cuestión distinta es que dichos límites no posean perfiles jurídicos complicados de gestionar o que no tengan un poderoso impacto sobre el funcionamiento del ELSJ. Tienen que tener ambos por necesidad.

\section{RECUPERANDO LA DIFERENCIA ENTRE CONFIANZA MUTUA Y RECONOCIMIENTO MUTUO DESDE LA PERSPECTIVA DE SUS LÍMITES «CONSTITUCIONALES»}

Un último aspecto, creo, es necesario aclarar: la configuración constitucional de los límites de la confianza mutua no resuelven la cuestión de los límites del reconocimiento mutuo, ni cuál es la posición que tiene ahí el respeto de los derechos fundamentales, porque solo resuelve el primero de los problemas de derechos fundamentales que mencionábamos al comienzo. Identificar cuándo ha desaparecido el presupuesto de la confianza mutua no resuelve, desde la perspectiva del respeto de los derechos fundamentales, ni las debilidades estructurales de las normas del antiguo tercer pilar ni las consecuencias de las opciones normativas arriesgadas o negligentes asumidas por el legislador europeo en el ELSJ. Y este es, a mi juicio, el gran peligro que la jurisprudencia sentada en este caso posee: la de entender que la cuestión de la relación entre reconocimiento mutuo y derechos fundamentales solo se resuelve en términos de confianza mutua, lo que en cierta medida ha sido favorecido por el propio Tribunal de Justicia con consecuencias perniciosas.

La confianza mutua (o cuándo esta se rompe) poco o nada tiene que ver con la falta de eficacia directa de las decisiones marco (que impiden al indi-

111 Iris CANOR, «My Brother's Keeper? Horizontal Solange: 'An Ever Closer Distrust Among the Peoples of Europe'», Common Market Law Review, vol. 50, 2013, p. 401. 
viduo valerse de ellas contra legem frente a la norma de transposición) o con sus opciones normativas arriesgadas o erróneas (como el establecimiento de umbrales penológicos exiguos para el uso de los instrumentos de cooperación judicial que posibilitan una utilización desproporcionada). Mientras que la obligación general de respeto de derechos fundamentales contemplada en el art. 1.3 de la Decisión Marco no sirve, más que tangencialmente, para resolver cuándo no existe confianza mutua, sí es el punto de partida (por innecesario que sea, atendido el art. 6 TUE o la propia Carta) para resolver el resto de estos problemas. Es aquí donde el Tribunal tiene por delante - y hasta ahora no ha hecho más que testimonialmente- construir una jurisprudencia claramente enderezada al respeto de los derechos fundamentales dentro del ELSJ, que reequilibre el anterior énfasis en la efectividad. Para ello dispone de instrumentos suficientes: el potencial efecto transformador del nuevo conjunto normativo post-Lisboa centrado en los derechos fundamentales de detenidos y procesados ${ }^{112}$, la interpretación conforme con la Carta del Derecho derivado pre- y post-Lisboa ${ }^{113}$, la primacía y eficacia directa de los principios generales del derecho de la Unión y de la Carta en los contextos aplicativos del derecho pre-Lisboa ${ }^{114} \mathrm{o}$ la exploración de las posibilidades que tiene la jurisprudencia Åkerberg en estos ámbitos ${ }^{115}$. Esto es, mientras que los problemas planteados

112 Valsamis MITSILEGAS, "Mutual recognition...», op. cit. nota 93, p. 167.

113 Quizás el ejemplo más sobresaliente — por contraste- lo proporciona la justamente criticada Sentencia de 27 de mayo de 2014, Spasic, C-129/14 PPU, EU:C:2014:586, donde el TJUE considera compatible con la Carta el art. 54 CAAS que sujeta el ne bis in idem a la existencia de que la pena se esté ejecutando. Es difícil sumar en pocas frases cuánto de erróneo hay en este pronunciamiento y, por consiguiente, cuánto margen tiene el TJUE para operar una interpretación pro derechos fundamentales, llegado el caso, extrayendo las consecuencias últimas de las deficiencias y lagunas del derecho de la Unión, no siendo una menor la insostenible regulación de los conflictos de jurisdicción en el ámbito penal (véase, por todos, John A.E. VERVAELE, «Schengen and Charter-related ne bis in idem protection in the Area of Freedom, Security and Justice: M and Zoran Spasico, Common Market Law Review, vol. 52, 2015, pp. 1348-1359).

114 Esta es la vía adecuada, a mi modo de ver, para resolver buena parte de los errores de la calificación como facultativos de ciertos motivos de denegación del reconocimiento (piénsese en los juicios en rebeldía o el condicionamiento en caso de penas a perpetuidad) o en la propia operatividad del principio de proporcionalidad tanto en la emisión como en la ejecución de la resolución judicial penal. Mientras que las decisiones marco están desprovistas de eficacia directa (y deben seguir estándolo), esa limitación no alcanza ni a los principios generales, ni a la Carta.

115 Véase el asunto $J Z$ supra nota 19. 
por la quiebra de la confianza mutua no pueden resolverse más que por vía de excepción a cargo de los demás Estados miembros, el resto de los problemas no requieren necesariamente asumir esa solución: en la medida en que son violaciones que están originadas por el derecho de la Unión, otros modos de garantizar que, como establece el art. 67 TFUE, el reconocimiento mutuo se produce con respeto de los derechos fundamentales, son articulables jurídicamente. De hecho, creo que dada la extraordinaria complejidad de las cuestiones jurídicas que se plantean (y algo de ello hemos visto al tratar de los perfiles técnico-jurídicos de esta sentencia) y la relevancia que aquí sí tiene el Derecho derivado, estos problemas no pueden resolverse mediante la aceptación, en términos de principios, de una excepción general, definida de forma más o menos amplia, al reconocimiento mutuo de resoluciones judiciales. Esto ha sido posible (y obligatorio), a mi juicio, en la definición de los límites «constitucionales» de la confianza mutua que esta sentencia Aranyosi y Căldăraru construye, pero no constituye una respuesta adecuada (ni, mucho menos, obligatoria por única) para los restantes problemas de respeto de los derechos fundamentales dentro del espacio de libertad, seguridad y justicia. 